\title{
Fracture mechanism of rock collapse in the freeze- thaw zone of eastern Sichuan-Tibet Mountains under seasonal fluctuating combinations of water and heat
}

\author{
Yong Wu ( $\nabla$ wyhongyu@163.com ) \\ 0002-9710-1144

\section{Xinpo Li} \\ Institute of Mountain Hazards and Environment Chinese Academy of Sciences \\ Lei Zhu \\ Institute of Mountain Hazards and Environment Chinese Academy of Sciences
}

Institute of Mountain Hazards and Environment Chinese Academy of Sciences https://orcid.org/0000-

\section{Research Article}

Keywords: rock collapse, fracture mechanics, seasonal temperature fluctuation, eastern Sichuan-Tibet, combination of water and heat

Posted Date: February 23rd, 2021

DOl: https://doi.org/10.21203/rs.3.rs-254606/v1

License: (c) (i) This work is licensed under a Creative Commons Attribution 4.0 International License.

Read Full License 
Fracture mechanism of rock collapse in the freeze-thaw zone of eastern Sichuan-Tibet Mountains under seasonal fluctuating combinations of water and heat

\author{
Yong $\mathrm{Wu}^{1,2, *}$, Xinpo $\mathrm{Li}^{1,2}$, Lei Zhu ${ }^{1,2}$ \\ ${ }^{1}$ Key laboratory of Mountain Hazards and Surface Process, CAS, Chengdu 610041, China \\ 2 Institute of Mountain Hazards and Environment, CAS, Chengdu 610041, China \\ * Corresponding author. E-mail address: wuyong@imde.ac.cn or wyhongyu@163.com
}

7 Abstract:

8 In the freeze-thaw zone of eastern Sichuan-Tibet Mountains, the phases of water in cracks show strong 9 seasonal variations, which significantly affect the stability of perilous rocks in mountains. However, 10 few works have clearly addressed the role of water/ice in crack development from a fracture mechanics

11 viewpoint to explain the seasonality of rock collapse. In this study, we built physical models from a 12 fracture mechanics viewpoint to calculate water-freezing stress, hydrostatic pressure, and their 13 combinations induced by water/ice in cracks, and show the crack propagation mechanism under 14 temperature fluctuations in different seasons in mountainous regions. Based on the models, we 15 calculate fracture conditions, simulate the crack process, and illustrate the rock collapse mechanism in 16 different seasons by the extended finite element method. The results indicate that different phases of 17 water, which induce stress under spatiotemporal fluctuations of temperature, determine the various 18 propagation styles and influence what kind and when a collapse will occur. The collapse of fractured 19 rocks in different seasons generally results from rock damage accumulation owing to the initiation, 20 propagation, and connection of primary cracks under freezing stress or hydrostatic pressure or their 21 different combinations.

22 Keywords: rock collapse, fracture mechanics, seasonal temperature fluctuation, eastern Sichuan-Tibet, 23 combination of water and heat

\title{
1 Introduction
}

Rock collapse widely occurs in the mountains of the eastern Tibetan Plateau owing to the 
27 geomorphic features of active crustal stress and large elevation differences. Especially in recent 50

28 years, the occurrence of rock collapse and avalanche disasters increase drastically (Hore et al. 2018).

29 These collapses and their secondary disasters pose danger to towns, roads, other inhabited regions.

30 Outstanding examples include the Yigong rock avalanche blocked the Yigong River for 2 months and

31 killed 94 people, the Baga collapse in Tibet dammed the Chayu River, and the Xinmo collapse-rock

32 slide in Sichuan buried 64 houses, caused dozens of people missing (Hu et al. 2018; Xu et al. 2012).

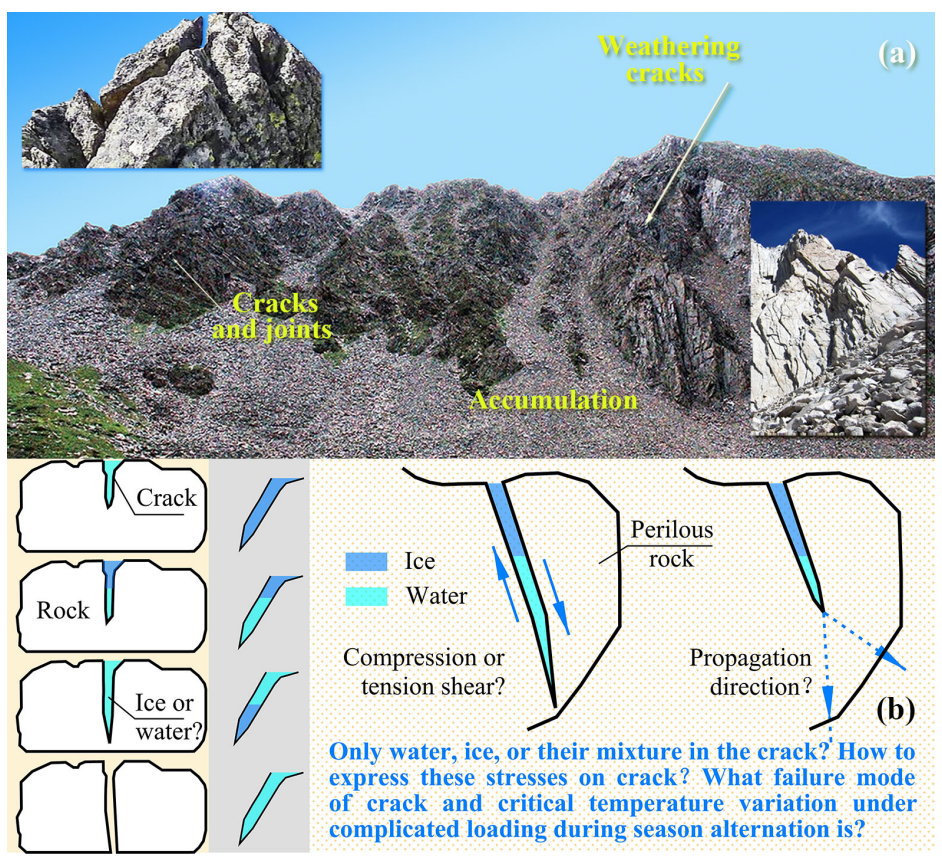

Fig. 1 Collapse bodies, perilous rock, and cracks in the mountains

Rock collapse is a process in which a relatively intact mass on a well-defined rupture surface rapidly detaches and undergoes extensive internal disaggregation, which directly leads to a rockslide or avalanche disaster (Eisbacher 1979). Many studies mainly focused on the dynamical mechanism of rockfalls or avalanches after collapses (Locat et al. 2006). Relatively few studies have clearly addressed the rock collapse mechanism, although the character, distribution law, and induced factors

40 of collapse have been well studied in a qualitative or semi-quantitative manner (Ez Eldin et al. 2013).

41 Nevertheless, these results cannot be used to explain how a collapse develops.

Field surveys in eastern Sichuan-Tibet Mountains have shown that the perilous rocks situated on 
43 steep scarps or cliffs are cut into crushes by various cracks (Chen et al. 2012) (Fig. 1a), and many

44 collapses occur along dominant cracks and mainly distribute at freeze-thaw zone. As shown in Fig.

45 1(b), these deep and controlled cracks are often filled by ice or water in different seasons and bear 46 complicated loads with the seasonal fluctuations of combined water and heat. This effect causes large 47 collapses in the late spring or early summer with increasing precipitation and temperature, and small 48 but frequent collapses when the temperature decreases in late autumn.

49 Many studies have shown that cracks influence rock stability. Panek et al. (2009) pointed out the 50 gradual propagation of cut surfaces weakens the rock mass and leads to collapse. Alippi et al. (2010) 51 suggested that rock collapse results from crack development in rocks. However, few studies have 52 elucidated how the cracks in perilous rocks develop and cause collapse.

53 Other studies have studied the effects of freeze-thaw action on rock-soil mass. Neaupane and 54 Yamabe (2001) researched the coupled thermo-hydro-mechanical model of frozen rock according to 55 continuum mechanics. Nicholson and Nicholson (2000) analyzed the freeze-thaw damage evolution 56 of rocks. Unfortunately, these studies did not involve the mechanism of collapses with deep cracks in 57 freeze-thaw mountainous settings (Fig. 1b).

58 Cracks and seasonal freeze-thaw actions are two sides of the same issue regarding rock collapse in 59 mountains. Primary cracks decrease the rock-soil mass strength, provide water channels, and facilitate 60 weathering. The freezing and thawing of water/ice in different seasons, in turn, extend the crack and 61 further reduces the rock stability. The effects of water and temperature on cracks in perilous rocks 62 hence take a significant role in collapse within the freeze-thaw zone. However, the environmental 63 conditions considering the seasonal effects of temperature and moisture on rock collapse remains an 64 open question in the eastern Sichuan-Tibet Mountains. Aside from preliminary studies regarding 65 collapse mechanism on different altitudes (Wu et al. 2020), few investigations have addressed the role 66 of water/ice in different seasons in crack development clearly from the viewpoint of fracture mechanics 67 and explained the seasonality of rock collapse. 
Hence, the major objective in our paper is to clearly study the rock collapse mechanism in the freeze-thaw zone of eastern Sichuan-Tibet Mountains from a fracture mechanics standpoint with consideration of phase change of water under seasonal fluctuations of surrounding temperatures. We analyzed the various water-heat combinations in different seasons and develop four models to characterize the driving forces of crack growth, including ice gravity, friction, water hydrostatic pressure, ice-induced stress, and their combinations. Based on these models, we calculated

74 SIFs (the stress intensity factors), and analyzed the stability of crack by the fracture mechanics. We gave the way to solve crack extension and studied quantitatively the effects of crack characteristics under the seasonal combination of water-heat on rock collapse patterns. Aided by XFEM (extended finite element method), we simulated the entire crack propagation eventually.

We first determined the research area and then built models of crack driving forces in perilous rocks under different water-heat environments based on the field survey. We calculated the crack initiation and propagation using XFEM and studied different variations on the crack models to explain the rock collapse mechanism under seasonal fluctuations of water and heat. We apply the results to practical examples to demonstrate the new theory of rock collapse.

\section{Background}

Various hazards including landslides and debris flow are widely distributed in the eastern Sichuan-

Tibet Mountains owing to complicated geology, neotectonic movement, geomorphology, and climate. Among them, rock collapse poses a serious threat to local inhabitants and usually results in rock avalanches/debris flows, which can block rivers and induce floods.

\subsection{Characteristics of nature environment}

The study area, Maojiagou gully, is located approximately $11.2 \mathrm{~km}$ southwest of Kangding town in Sichuan, China. As shown in Fig. 2, many important transport lines, such as the G318 national road and Sichuan-Tibet railway (under construction), pass across near this area. The mountain slopes in the 
92 study area are very steep and thus numerous potential rock detachment zones develop on both sides of

93 the valley. Maojiagou gully has a subtropical mountain monsoon climate. The local meteorological

94 data show that the maximum and minimum values of average monthly air temperatures are $8.3^{\circ} \mathrm{C}$ and

$95-14.1{ }^{\circ} \mathrm{C}$ at the gully mouth respectively (3220 $\mathrm{m}$ altitude). The precipitation is about $810 \mathrm{~mm}$ a year

96 and nearly $80 \%$ occurs in summer from May to September. The Zheduohe River flows through the

97 front of the Maojiagou gully from northwest to southeast.

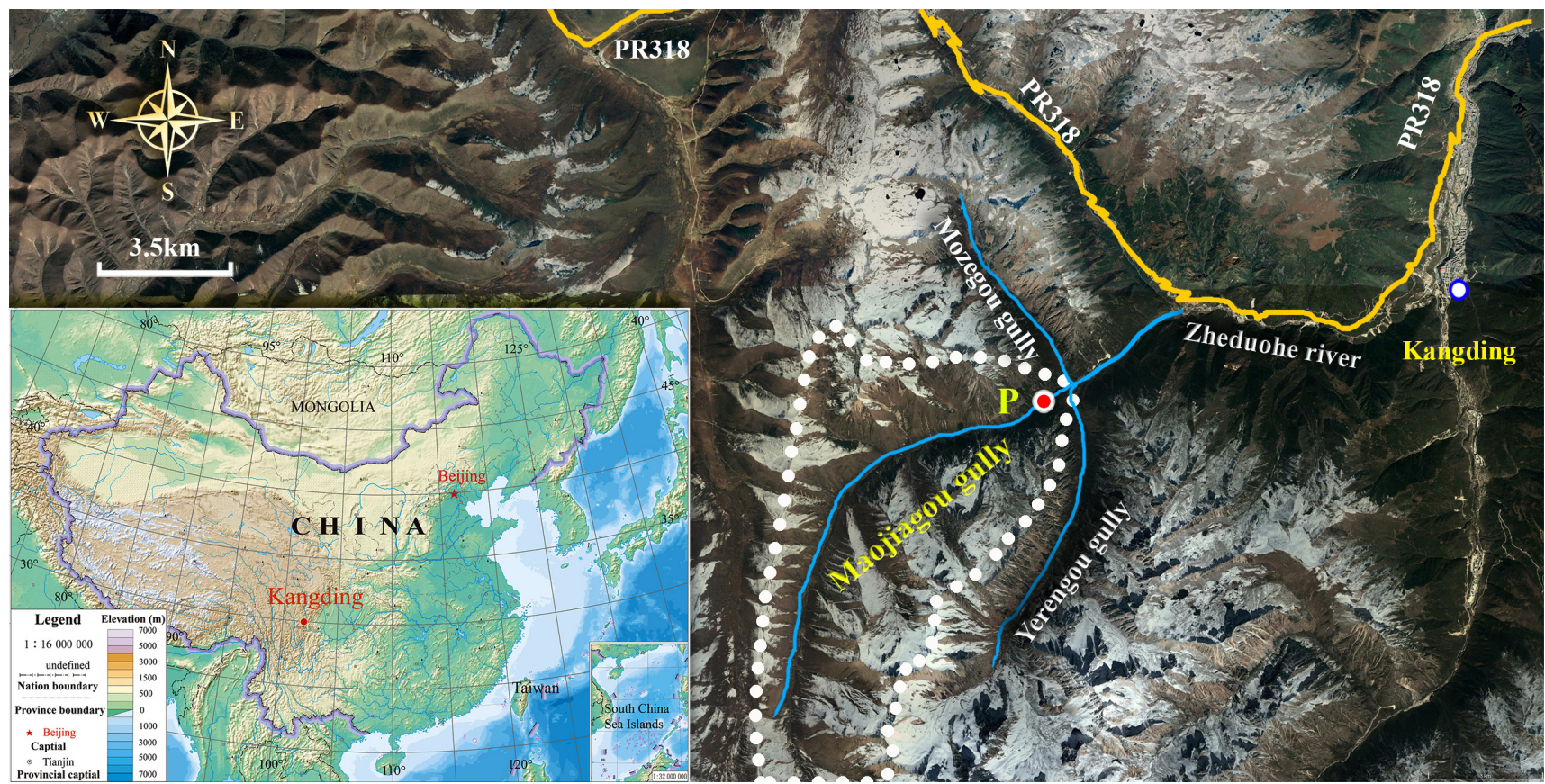

Fig. 2 The location of the study point.

\subsection{Geological and slope structure}

Two active geologic tectonic structures are present in the study area: the SW-NE oriented

102 Longmenshan thrust fault and the SE-NW oriented Xianshuihe strike-slip fault belts, which intersect

103 nearby. Due to vigorous tectonic activity, the rock strata are heavily fragmented and the fracture

104 development extensively. The exposed lithology within the study area mainly weathered granite,

105 metamorphic granite and plagiogranite with intense disintegration, which enhances the development

106 of high-risk rock zones (Fig. 3a and b). The gully bed is thus vulnerable to valley rock avalanches

107 caused by several large collapses at different altitude positions of the mountain on both valley slopes. 
108 At the study point $\mathrm{P}\left(29^{\circ} 58^{\prime} 00^{\prime \prime} \mathrm{N}, 101^{\circ} 50^{\prime} 30^{\prime \prime} \mathrm{E}\right)$, the elevations of the highest collapse and mountain

109 feet are approximately 4600 and $3580 \mathrm{~m}$, respectively, with an average slope angle of approximately

$11034.2^{\circ}$. A variety of loose Quaternary accumulation is distributed on the inclinations or foot of the slope.
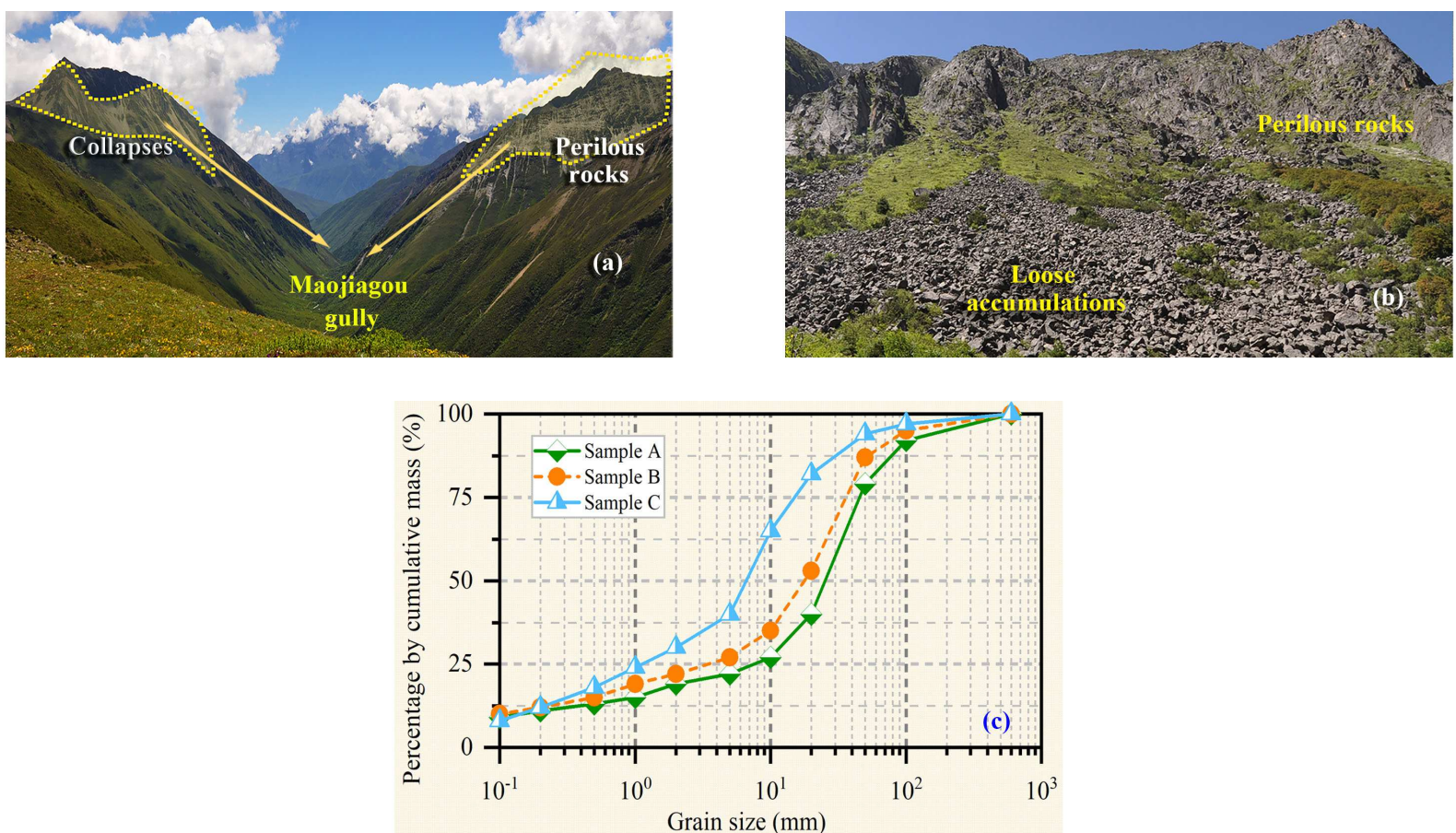

Fig. 3 Collapses in Maojiagou gully and the character of their deposits

\section{apse and accumulation}

115 Through field surveys, we obtained the basic parameters of the collapse: position; slope angle; accumulation volume; and particle size.

According to the survey data, the region in which the collapses occur is mainly between the

118 snowline and timberline. In this region, the temperature frequently varies around zero in different

119 seasons, hence the freeze-thaw action of the soil-rock body is intensive. Most fractured rocks are easily

120 broken under hydraulic splitting or ice wedging forces with temperature fluctuations.

121 Rock collapses can occur in this region during any season but are more common in early spring, a

122 rainy summer, and late autumn. They widely distribute in the freeze-thaw alternation area or near the

123 glacial retreat area caused by global warming. Their accumulations are not thick or far from the source.

124 The particles vary in size, shape, and sorting owing to different formation mechanisms, but aside from 
some meter-scale boulders, most particles are small on the $\mathrm{mm}$ to $\mathrm{cm}$ scale.

To determine the characteristics of collapse particles, we collected accumulation source material in the Maojiagou gully and tested the distribution of grain size. As shown in Fig. 3(c), the dimensions of $91.6 \%$ of previous fall particles from situ collapse accumulations observed on the slope or gully are 130 rock collapse.

\subsection{Qualitative analysis of collapse in the freeze-thaw zone of mountains during different seasons}

The temperature in mountains shown in Fig. 4 drops by $0.6{ }^{\circ} \mathrm{C}$ with an elevation rise of $100 \mathrm{~m}(\mathrm{Du}$ surface temperature data mentioned in Section 2.1.

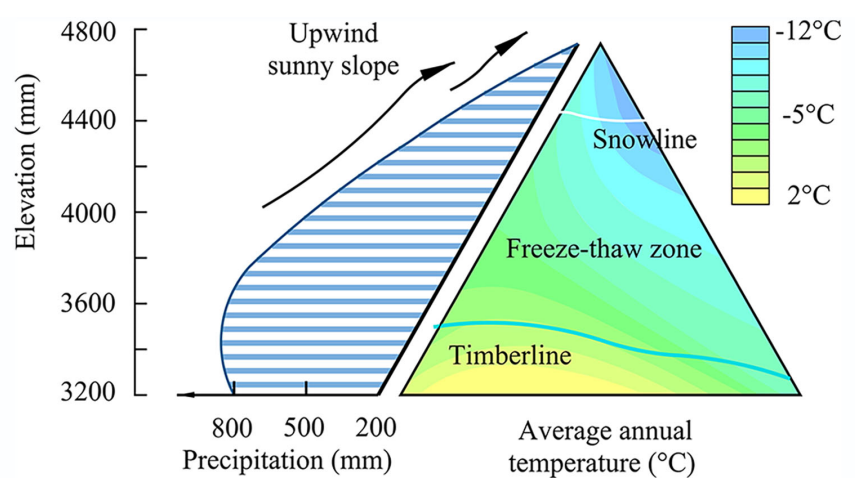

Fig. 4 Sketch of water-heat combination in mountains of the study area.

138 As shown in Fig. 5(a, b), as geologic bodies, perilous rocks contain numerous primary fractures (e.g., 139 cracks, joints, faults), many of which are filled with snow or ice in the high mountains of the study 140 area. Because ice mechanics is sensitive to temperature, the stability of ice-filled cracks is influenced 141 by changes of water-heat combinations at different altitudes and/or in different seasons. The survey 142 revealed that fractures mainly distribute on the surface of perilous rocks and penetrate too far smaller 143 depths than climate-influenced depths. Hence, the temperature of filled cracks is directly affected by 144 the atmosphere and can be assumed to be the same as the local air temperature (Table 1). 
Maximum and minimum average monthly temperatures estimated at different altitudes.

\begin{tabular}{cccccccccc}
\hline Altitude $(\mathrm{km})$ & $\mathbf{3 . 2 2}$ & $\mathbf{3 . 5 8}$ & 3.6 & 3.8 & 4.0 & 4.2 & 4.4 & 4.6 & 4.8 \\
\hline Maximum in summer $\left({ }^{\circ} \mathrm{C}\right)$ & 8.3 & 6.1 & 6.0 & 4.8 & 3.6 & 2.4 & 1.2 & 0.0 & -1.2 \\
Minimum in winter $\left({ }^{\circ} \mathrm{C}\right)$ & -14.1 & -16.3 & -16.4 & -17.6 & -18.8 & -20.0 & -21.2 & -22.4 & -23.6 \\
\hline
\end{tabular}

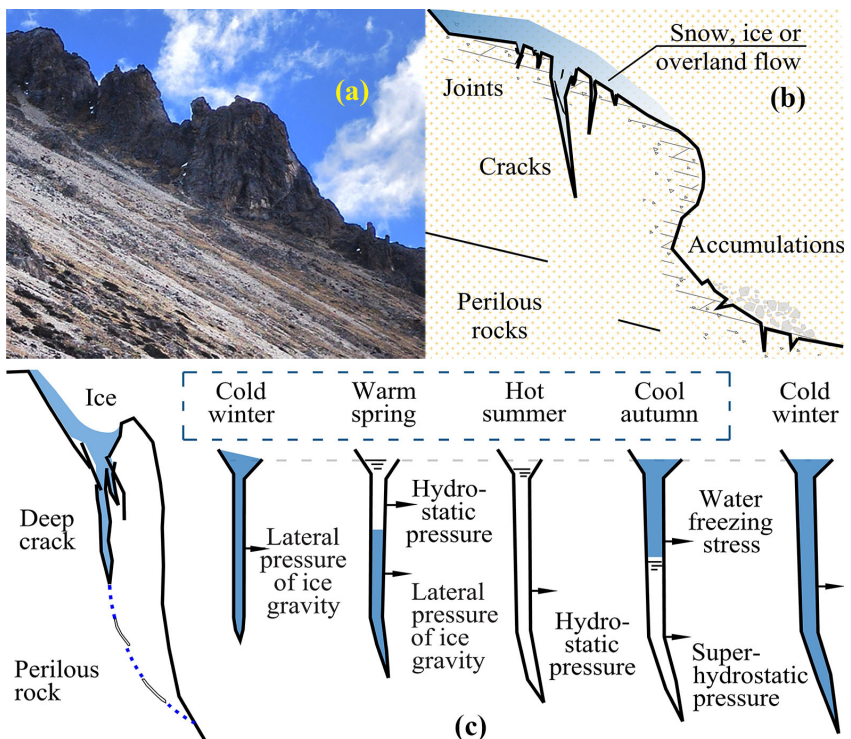

Fig. 5 Idealized schematic diagram of (a-b) perilous rock and (c) the cracking process in different seasons

149 Moreover, the temperature of cracks in the study area changes and varies seasonally. At altitudes

150 lower than $3800 \mathrm{~m}$, the temperature typically decreases below zero in cold seasons and rises above

151 zero in warm seasons, which induces serious freezing stress in autumn or winter and high hydrostatic

152 pressure in spring or summer. When the altitude is $3800 \mathrm{~m}$ and higher, the temperature is negative

153 year-round and freezing stress dominates the development of perilous rocks.

154 Data from the field investigation also indicate that seasonal freezing and hydraulic splitting under 155 different water-heat combinations contribute to the collapses in study area. Hence, to illustrate the 156 entire propagation process of cracks in different seasons, the influence of water phase changes at 157 different temperatures on the collapse mechanism in mountains must be considered (Fig. 5c).

\section{Models of crack stress caused by filled water/ ice in perilous rock with season variation}

For simplicity, we idealized the perilous rock as a 2D model in Fig. 6 with a major crack that is $l$

160 long, $w$ wide, and $\theta$ incline. Here taking the crack mouth as the origin, the $x$-axis is built along the 
cracks and make assumptions as follows:
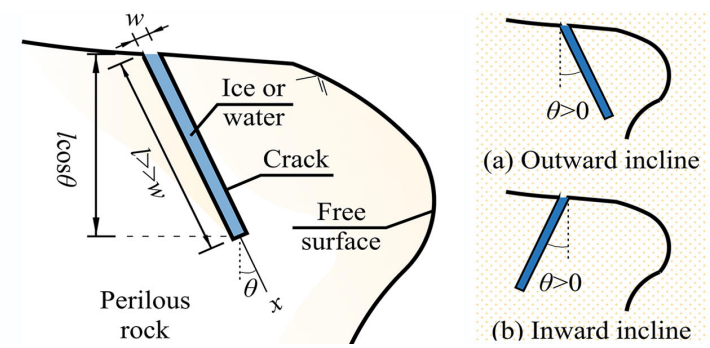

Fig. 6 Model for crack propagation in perilous rocks. Note the angle $\theta$ is positive when the crack inclines outward.

a) The water in the crack is incompressible but the ice is elastic. The constraint provided by crack is rigid prior to initiation and propagation.

b) The ice in the crack is a rigid elastic solid, which has a high cohesion $(0.5-1 \mathrm{MPa})$ and can form dry calving cliffs or deep cracks with tens of meters in depth in a real iceberg (Bassis and Walker 2011). Hence the lateral pressure on the crack induced by ice gravity does not to be considered.

c) Due that the temperature of filled cracks is seen as the same as the local air temperature according to section 2.4, the water-ice phase change can thus occur instantaneously without considering the hysteresis process of heat conduction.

d) The crack surface is rough and the friction with the ice induced by ice gravity must be considered, although its influence on cracking is typically less than that of the transverse stress induced by ice expansion.

e) The width $w$ of the crack is substantially smaller than its length $l$. Hence, ice expansion along the $\mathbf{x}$-axis can be neglected and no shear strain nor friction occurs due to ice expansion.
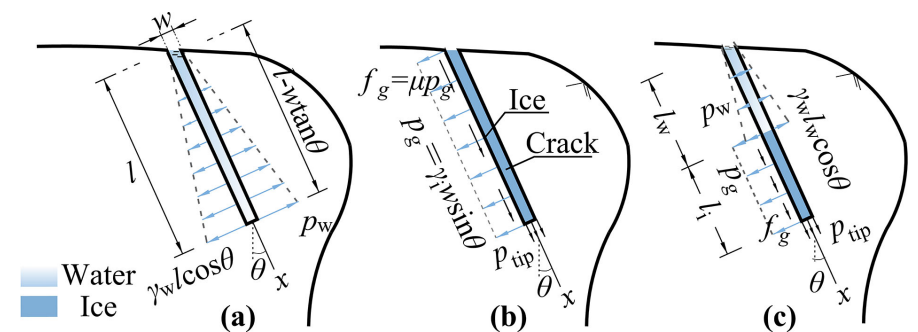

Fig. 7 Stress on the surface (a) of a water-filled crack in summer, (b) of an ice-filled crack in winter, and (c) when the ice 179 melts with increasing temperature in spring 


\subsection{Hydrostatic pressure on the surface of a water-filled crack in hot summer}

Studies revealed that the frequency of rockfalls significantly increases in mountainous permafrost areas during warm months, and attributed this phenomenon to the loss of ice-bonded forces when

183 filling ice melts and emphasized that the disappearance of the 'adhesion' of ice to rock cause the failure 184 (Dramis et al. 1995). However, these studies do not explain how cracks develop and how damage accumulates for a rock slope that is stable prior to being filled with ice. Here, we propose that the meltwater of ice during warm weather or abundant rainfall in rainy seasons fill the cracks, generating hydrostatic pressure and causing hydraulic fracturing. As shown in Fig. 7(a), the triangular distribution of hydrostatic pressure acting on a crack surface:

$$
p_{\mathrm{w}}=\gamma_{\mathrm{w}} x \cos \theta \quad 0 \leq x \leq l
$$

190 where $\gamma_{\mathrm{w}}$ is water's unit weight. Obviously, at the crack tip, its maximum value is $\gamma_{\mathrm{w}} l \cos \theta$.

191 Note the length of the immersion surface differs on either side of an inclined crack, thus real 192 hydrostatic stress on both surfaces is only expected to be similar (but different). However, in our study, 193 the crack length is substantially longer than its width, hence a reasonable approximate value is given 194 as Eq. (1).

\subsection{Stress on surface of an ice-filled crack in cold winter}

In cold winter, water in cracks completely freeze. There are two stresses on the crack surface (Fig. $7 \mathrm{~b})$, one is the gravity components perpendicular to the crack:

$$
p_{g}=\gamma_{\mathrm{i}} w \sin \theta
$$

where $p_{\mathrm{g}}$ is the normal pressure on the low surface caused by ice gravity, $\gamma_{\mathrm{i}}$ is ice's unit weight.

201 direction, which can be expressed based on the above assumption as:

$$
f_{g}=\mu p_{g}=\mu \gamma_{\mathrm{i}} w \sin \theta
$$


where $f_{g}$ is the surface friction and $\mu$ is the friction factor between ice and rock, which depends on temperature and is $<0.1$ for the lubrication of melting of ice at a high negative temperature $\left(>-10{ }^{\circ} \mathrm{C}\right)$ (McCarthy et al. 2017). The x-component of ice gravity $\gamma_{\mathrm{i}} l \cos \theta$ can thus not be balanced only by friction in Eq. (3) and imposes a residual pressure on the crack tip as follows:

$$
p_{\text {tip }}=\gamma_{\mathrm{i}} l(\cos \theta-\mu \sin \theta)
$$

208 where $p_{t i p}$ is the pressure on the crack tip caused by ice gravity.

\subsection{Stress on the surface of an ice-water-filled crack upon increasing temperature in warm spring}

Upon the arrival of spring, the ice within cracks begins to melt with temperature rise. As shown in Fig. 7(c), meltwater in the upper section of a crack with length $l_{\mathrm{w}}$ poses a hydrostatic pressure (Eq. 1) on the crack surface. For the low crack segment $\left(l_{\mathrm{i}}\right)$, the ice gravity results in normal pressure $p_{\mathrm{g}}$ and friction $f_{g}$ on the lower surface, as given in Eqs. $(2,3)$.

The friction $f_{g}$ caused by the normal component of ice gravity in Eq. (3) cannot usually balance the ice gravity component $\gamma_{i} l \cos \theta$, let alone the maximum hydrostatic pressure imposed on top of the ice column. Hence, residual pressure is generated on the crack tip as:

$$
p_{\text {tip }}=\gamma_{\mathrm{i}} l(\cos \theta-\mu \sin \theta)+\gamma_{\mathrm{w}} l_{\mathrm{w}} \cos \theta
$$

where $p_{\text {tip }}$ is the pressure induced by ice gravity on the tip of crack.

\subsection{Stress on surface of an ice-water-filled crack when the temperature drops in cool autumn}

When the crack water begins to freeze with the temperature drop, it undergoes a 0.09 expansion for freezing and can expand nearly to 0.135 linearly at $-22^{\circ} \mathrm{C}$, thus an outward force generates on crack and wedges the rock apart (Hallet 2006). On the assumption that the crack can provide a rigid constraint prior to cracking and ice strain only occurs perpendicular to the crack surface, the freezing stress applied on the crack is expressed as:

$$
p_{\mathrm{i}}=\varepsilon(t) \cdot E(t)=E(t)\left(0.09-\frac{0.045}{22} t\right)
$$


where $E(t)$ is ice elastic modulus (MPa) and is expressed as 6600(1-0.012t) (Godbout et al. 2000), $\varepsilon(t)$

227 is the strain, $t$ is the temperature $\left({ }^{\circ} \mathrm{C}\right)$. Considering the ice exhibits viscous-plastic behavior under high

228 pressure although it is brittle under most natural conditions, the freezing stress may be overestimated

229 by Eq. (6) and need to be modified with a correction factor (0.185) (Wu et al. 2020).

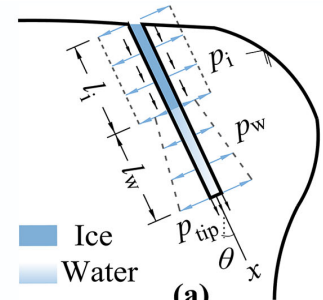

(a)

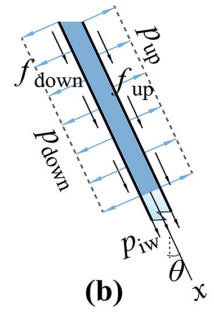

(b)

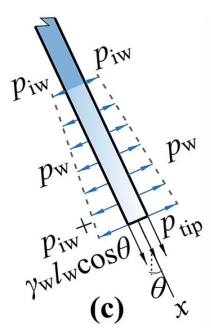

(c) ${ }^{\theta} x$

Fig. 8 Stress on ice-water-filled crack when the temperature drops in cool autumn

232 Natural water in cracks is usually gradually frozen from the top (crack mouth) to the bottom (crack

233 tip) with decreasing temperature. In most cases (Fig. 8a), when the weather becomes cool in autumn,

234 a water-filled crack in cold mountains will be filled with ice on the upper segment $\left(l_{i}\right)$ and water on the 235 lower segment $\left(l_{w}\right)$.

(a) Stress on the upper segment of the crack surface

Because of the normal component of the ice gravity given normal to surface in Eq. (2), the pressure on each side of the crack surface in Fig. 8(b) differs as:

$$
\left\{\begin{array}{l}
p_{\text {up }}=p_{\mathrm{i}} \\
p_{\text {down }}=p_{\mathrm{i}}+\gamma_{\mathrm{i}} w \sin \theta
\end{array}\right.
$$

241 gravity along the $\boldsymbol{x}$-direction. In most cases, the friction is sufficient to support the ice pillar and can 242 be expressed as:

$$
\left\{\begin{array}{l}
f_{\text {up }}=\frac{p_{\text {up }} \gamma_{\mathrm{i}} w \cos \theta}{p_{\text {up }}+p_{\text {down }}} \\
f_{\text {down }}=\frac{p_{\text {down }} \gamma_{\mathrm{i}} w \cos \theta}{p_{\text {up }}+p_{\text {down }}}
\end{array}\right.
$$

244 where $p_{\text {down }}, p_{\text {up }}, f_{\text {down }}$ and $f_{\text {up }}$ are the pressure and friction on each side of the surfaces of the crack. 
However, when the bearing capacity provided by the surface along the $x$-direction is less than the

246 gravity component $\gamma_{\mathrm{i}} w \cos \theta$, the friction on the surface and excess hydrostatic pressure generated on

247 water in lower segment of crack are:

$$
\left\{\begin{array}{l}
f_{\text {up }}=\mu p_{\text {up }} \\
f_{\text {down }}=\mu p_{\text {down }} \\
p_{\text {iw }}=\gamma_{\mathrm{i}} l \cos \theta-\mu\left(p_{\text {up }}+p_{\text {down }}\right)
\end{array}\right.
$$

249 where $p_{\text {iw }}$ is the excess hydrostatic pressure generated by water, which together with friction on the 250 surface uphold the upper ice.

\section{(b) Stress on the lower segment of the crack surface}

On the lower crack surface, not only the hydrostatic pressure induced by water gravity in Eq. (1)

but also the excess hydrostatic pressure $p_{\text {iw }}$ in Eq. (9) occur. The surface pressure in Fig. 8(c) is thus:

Specially on the crack tip, the pressure reaches its maximum value of $\gamma_{\mathrm{w}} w \sin \theta+p_{\text {iw }}$.

The temperature fluctuates during not only the transition between seasons but also between day and night. Especially in warm spring or cool autumn, the temperature can fluctuate above or below the 258 freezing daily. The above model includes the process of crack cooling/heating and can be used to 259 illustrate crack propagation with daily temperature changes in the same way.

\section{Mechanism of cracking and its simulation}

To study the fracture mechanism of rock collapse in the freeze-thaw zone of eastern Sichuan-Tibet

262 Mountains based on the above models, we review the criteria of crack initiation, study the crack 263 extension and use XFEM to simulate cracking according to fracture mechanics.

\section{$264 \quad 4.1$ Criteria of crack initiation}

In fracture mechanics (Erdogan and Sih 1963), modes I and II SIFs $K_{\mathrm{I}}$ and $K_{\mathrm{II}}$ induced by ice 
gravity, ice expansion forces, friction, and hydrostatic pressure given in section 3 must satisfy the following formulations to maintain crack stability:

$$
\left\{\begin{array}{l}
K_{\mathrm{I}} \sin \varphi=K_{\mathrm{II}}(1-3 \cos \varphi) \\
K_{0} \leq K_{\mathrm{C}}
\end{array}\right.
$$

where $K_{0}=\cos (0.5 \varphi)\left[K_{\mathrm{I}} \cos ^{2}(0.5 \varphi)-1.5 K_{\mathrm{II}} \sin (\varphi)\right]$ is a compound value of SIF considering both contributions of modes I and II fracturing, $K_{\mathrm{C}}$ is the rock fracture toughness, and $\varphi$ is the fracture angle, which is measured anticlockwise from the original crack direction (Fig. 9).

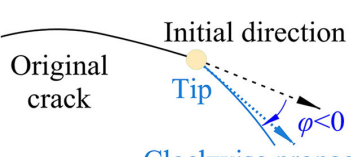

Clockwise propagation

(a)

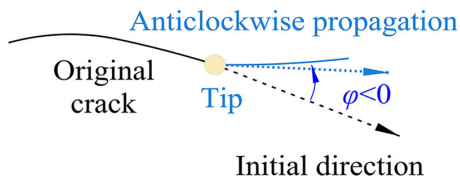

(b)

Fig. 9 Schematic diagram of the crack propagation direction

By solving these formulas, the fracture angle and critical stress that determine the initiation of crack failure can be obtained.

\subsection{Crack extension (length) after initiation and propagation}

Most deep cracks of perilous rocks continue to extend after initiation to propagate and lead to collapse due to increasing water depth and hydrostatic pressure during abundant rainfall, unless the propagation direction or extension path is not suitable for failure.

However, for cracks that initiate to propagate under water-freezing stress, their extension would be exist during a continuous cooling process.
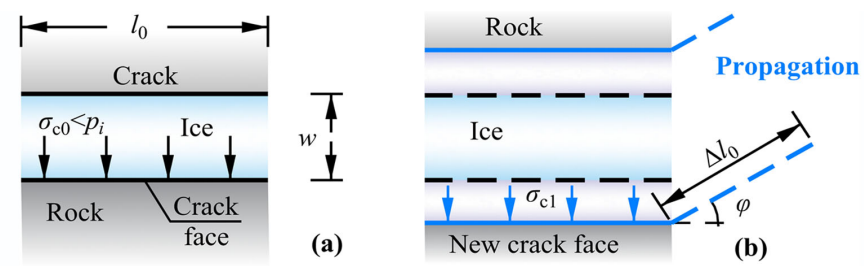

Fig. 10 Calculation sketch of the crack propagation length

In this case, the freezing stress on a crack would continue to decline from the maximum value (Eq. 
286 6) with ongoing propagation. When the stress becomes lower than its critical value, extension 287 eventually terminates. Thus, the releasing strain of ice during this process (Fig. 10) can be given as:

$$
\Delta \varepsilon=\varepsilon_{0}\left(1-\frac{\sigma_{c 1}}{p_{i}}\right)=0.09-\frac{0.045}{22} t_{0}-\frac{\sigma_{c 1}}{E\left(t_{0}\right)}
$$

289 where $\sigma_{\mathrm{c} 1}$ is the critical stress that determines whether a crack $\left(l_{0}\right)$ with a propagation length $\left(\Delta l_{0}\right)$ 290 initiates and propagates or not, $p_{\mathrm{i}}$ and $\varepsilon_{0}$ are the freezing stress on the crack and free strain of ice after 291 crack propagation, respectively, when the temperature drops from zero to $t_{0}$, and $\Delta \varepsilon$ is the release of 292 ice strain during crack opening.

293 Note that the freezing stress in Eq. (6) is a maximum value on the assumption that the crack can 294 provide a rigid constraint prior to initiation. However, when the freezing stress exceeds the critical 295 stress $\left(\sigma_{\mathrm{c} 0}\right)$, the crack begins to propagate and the stress no longer increases. Hence, the work of 296 freezing stress on cracks with unit width (along the horizontal extension direction of the perilous slope) 297 can be calculated as:

$$
W=\frac{\sigma_{c 0}+\sigma_{c 1}}{2} \cdot w \cdot \Delta \varepsilon \cdot l_{0}
$$

299 where $\sigma_{\mathrm{c} 0}$ is the critical stress that causes the initiation of a crack with an original length $\left(l_{0}\right), w$ is the 300 crack width, and $W$ is the work of the freezing stress.

According to Griffith theory (Griffith 1921) of fracturing, the extension length of a crack is:

where $\Delta l_{0}$ is the propagation length, $G_{\mathrm{C}}$ is the energy release rate.

\subsection{Numerical simulation according to XFEM}

Crack loading conditions are complicated in nature, which makes it difficult to analyze the fracture mechanism of rock collapses using an analytical solution. Numerical methods provide a simple way to analyze and visualize the crack propagation process and its impacts on perilous rock stability. For 
example, by coupling with J-integral methods, FEM is a common way to evaluate SIFs. However, near the tip of crack, the mesh needs to be refined and conforms to the crack geometry, which cause inaccurate fracture mechanics solutions and cost expensive computationally.

In this study, we use XFEM added with high-order terms (Wang and Waisman 2018) to solve our

312 fracture problems, which alleviate the cost of re-meshing with crack propagation and offer a more 313 accurate solution near the crack tip. the Heaviside function $L(x)$ used to describe the displacement jump 314 on the crack face and the XFEM displacement approximation $\mathbf{u}^{h}(\boldsymbol{x})$ are as we mentioned in our work 315 (Wu et al. 2020):

$$
\left\{\begin{array}{l}
L(x)= \begin{cases}+1 & \text { above crack } \\
-1 & \text { below crack }\end{cases} \\
\mathbf{u}^{h}(x)=\sum_{O \in S} N_{O}(x) \mathbf{u}_{O}+\sum_{O \in S_{T}} N_{O}(x) \sum_{\alpha=1}^{n} f_{a}(x) \mathbf{b}_{a O}+\sum_{O \in S_{L}} N_{O}(x) L(x) \mathbf{a}_{O}
\end{array}\right.
$$

317 where $\mathbf{u} o$ denoted by $N_{O}(x)$ is the standard FE shape functions related to the DOF (standard degree of

318 freedom), $x$ represents the spatial coordinate, $S_{L}$ is the node-set which can be split by crack entirely, $S_{T}$ 319 is node-set located in the crack tip to support their basis functions, while $S$ represents the domain node320 sets. $f_{a}(\boldsymbol{x})$ are crack-tip branch functions expressed by terms of $(r, \theta)$ in polar coordinates taking the 321 origin on the tip, $\mathbf{a}_{o}$ and $\mathbf{b}_{a O}$ are DOFs of nodes corresponding to functions $L, f_{a} . n$ is the number of enrichment functions using near-tip asymptote.

\section{Calculation and analysis}

According to the field survey in the study area, we take perilous rock of the most common dimensions as an example to illustrate the fracture mechanism of rock collapse in a freeze-thaw zone. As shown in the 2D model in Fig. 11(a), the width (not including the crack width) and height of the perilous rock is $3.7 \mathrm{~m}$ and $3.5 \mathrm{~m}$ respectively. A crack with a length of $1.3 \mathrm{~m}$ and vertical inclination of $10^{\circ}$ develops at the upper part of the rock within $2.0 \mathrm{~m}$ to the far-right end (point $\mathrm{D}$ ) of the rockfree face. In the model, all the degrees of freedom on the bottom BC and horizontal degree of freedom 
on boundary $\mathrm{AB}$ are fixed.

331 To quantitively carry out a parametric study on SIFs and fracture angles, we model the free face of

332 the perilous rocks as a double broken line ODC in Fig. 11(b), where the horizontal inclination of OD

333 is $20^{\circ}$ and the vertical inclination of DC is $a$. The crack length and vertical inclination are expressed

334 as $l_{0}$ and $\theta_{0}$, respectively. Note that all these parameters are sensitive to the specific different calculation

335 purposes, as described in section 5.4. The stress on the crack induced by hydrostatic or ice expansion

336 pressure can be given according to Eqs. (1-10).
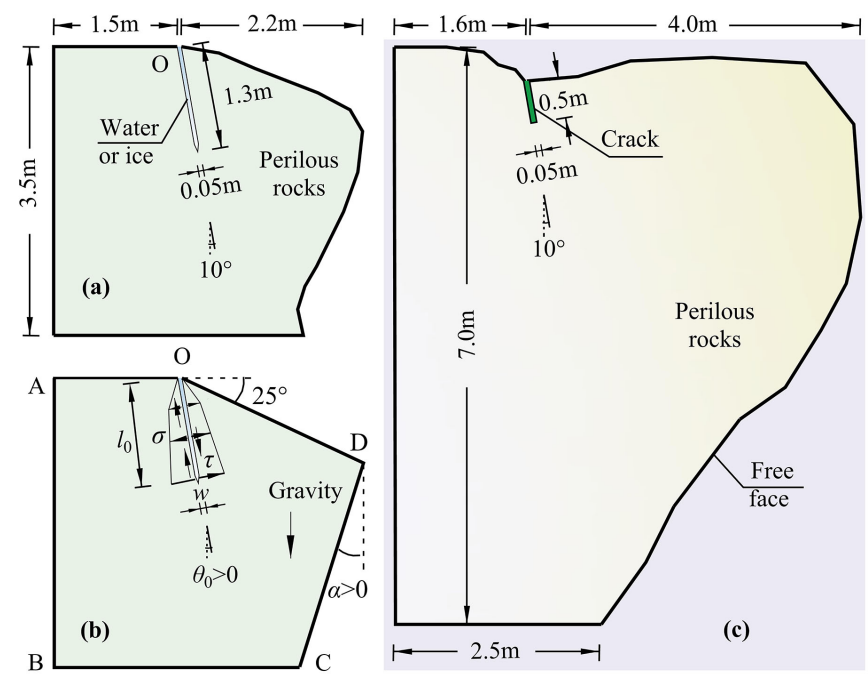

Fig. 11 Computational analysis model of perilous rocks.

\subsection{Material properties}

Granite samples are medium-fine-grained biotite granite collected from the collapse accumulation

341 site, which has a grayish-white and blocky structure. As an igneous rock, the samples mainly consist

342 of $41.2 \%$ microcline, $22.4 \%$ quartz, and $27.3 \%$ plagioclase. Experiments such as density test and MTS

343 (Mechanical Testing \& Simulation) test (Fig. 12) were carried, and the properties of rock are obtained

344 (Table 2). The standard geometrical dimensions of the specimens used to test the fracture mechanics

345 properties are given in Figs. 12(b, c).

346 Table 2

347 Calculation parameters of the model

\begin{tabular}{cccc}
\hline Parameters & water & Ice $\left(0^{\circ} \mathrm{C}\right)$ & granite \\
\hline$\rho\left(10^{3} \mathrm{~kg} / \mathrm{m}^{3}\right)$ & 1.0 & 0.9 & 2.8
\end{tabular}




\begin{tabular}{cccc}
$E\left(10^{9} \mathrm{pa}\right)$ & - & 6.6 & 41 \\
$G\left(10^{9} \mathrm{pa}\right)$ & - & 2.48 & 16.4 \\
$v$ & - & 0.33 & 0.25 \\
$R_{c}(\mathrm{MPa})$ & - & - & 22.52 \\
$R_{t}(\mathrm{MPa})$ & - & - & 2.75 \\
$K_{\mathrm{C}}\left(\mathrm{MPa} \cdot \mathrm{m}^{1 / 2}\right)$ & - & - & 0.806 \\
$G_{\mathrm{c}}\left(\mathrm{kJ} / \mathrm{m}^{2}\right)$ & - & - & 0.015 \\
\hline
\end{tabular}
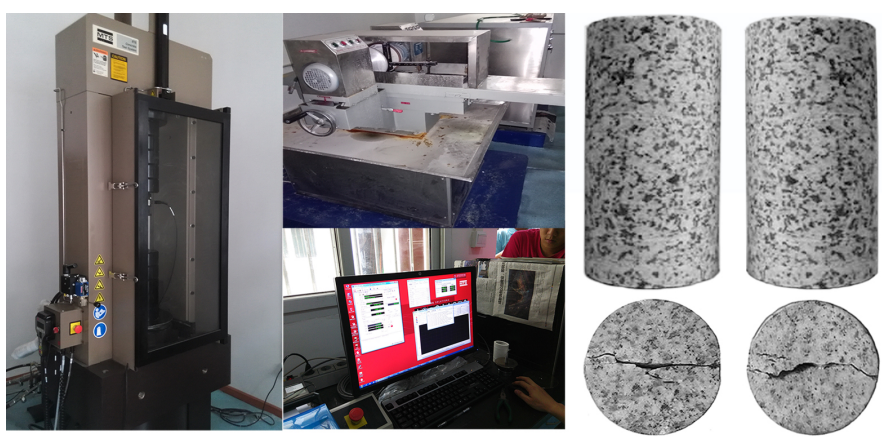

(a) Experimental instrument and specimens

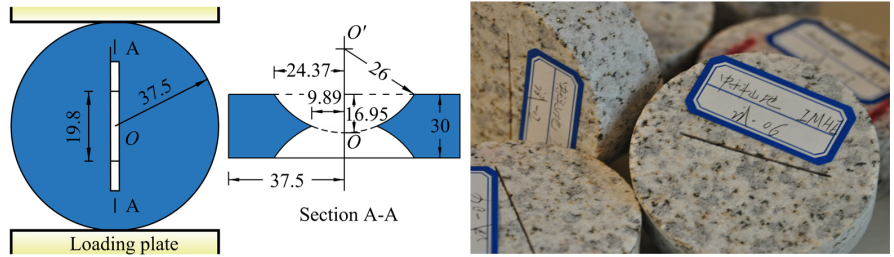

(b) The geometry of a CCNBD specimen

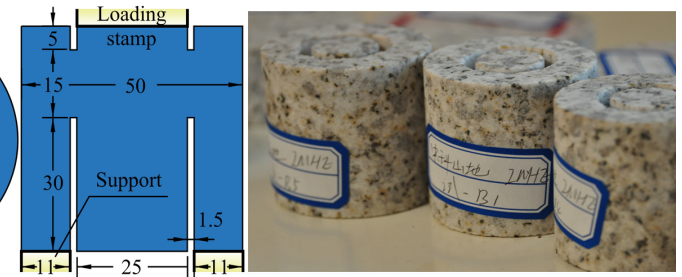

(c) The geometry of a PTS/CP specimen

Fig. 12 Mechanical property test of granite

According to CCNBD test (Fowell et al. 1995) and PTS/CP experiment (Backers and Stephansson

351 2012), the fracture toughness is:

$$
\left\{\begin{array}{l}
K_{\mathrm{IC}}=0.10224 P_{\max } \\
K_{\mathrm{IIC}}=7.74 \times 10^{-2} F_{\text {max }}-1.80 \times 10^{-3} P_{c}
\end{array}\right.
$$

353 where $P_{\max }$ is the yield load $(\mathrm{kN}), P_{\mathrm{c}}$ is the confining pressure $(\mathrm{MPa}), F_{\max }$ is the peak load $(\mathrm{kN}) . K_{\mathrm{IC}}$, $354 K_{\text {IIC }}$ represents the I/II mode fracture toughness $\left(\mathrm{MPa} \cdot \mathrm{m}^{0.5}\right)$.

355 The crack energy release rate $G_{\mathrm{c}}$ is given as $K_{\mathrm{C}}^{2}\left(1-v^{2}\right) / E$, and $K_{\mathrm{C}}$ can be obtained in Eq. (11).

\section{$356 \quad 5.2$ Parametric study on fracture characters}


Under seasonal fluctuations of water-heat combinations, rock collapse is determined by whether a

crack in the perilous rock can fracture and along which direction and how far it propagates. All of these

359 can be estimated by some fracture factors, such as SIFs, fracture angles, and propagation length, which

360 are usually affected by the geometry of the crack or perilous rock and ambient temperature variation.

361 Considering the seasonal change of temperature and rainfall, extensive parametric studies including

362 the perilous rock geometry characteristics and ambient temperature (cases 1 to 7, Table 3) were

363 conducted as follows:

364 Table 3

365 Geometric data of perilous rock and temperature data in the parametrical study

\begin{tabular}{|c|c|c|c|c|c|c|c|}
\hline \multirow{2}{*}{\multicolumn{3}{|c|}{$\begin{array}{c}\text { Hydrostatic pressure } \\
\text { rainy seasons } \\
\text { late spring or summer }\end{array}$}} & \multirow{2}{*}{\multicolumn{3}{|c|}{$\begin{array}{c}\text { Freezing stress } \\
\text { cooling seasons } \\
\text { autumn or early winter }\end{array}$}} & \multicolumn{2}{|c|}{$\begin{array}{l}\text { Hydrostatic pressure }+ \text { stress } \\
\text { induced by }\end{array}$} \\
\hline & & & & & & \multirow{2}{*}{$\frac{\text { freezing stress }}{\text { Case F }}$} & \multirow{2}{*}{$\frac{\text { ice gravity }}{\text { Case } \mathrm{G}}$} \\
\hline & Case A & Case B & Case C & Case D & Case E & & \\
\hline$l_{0}(\mathrm{~m})$ & $\begin{array}{c}0.4 / 0.7 / 1 / 1.3 / \\
1.6 / 1.9 / 2.2 / 2.5\end{array}$ & 1.3 & 1.3 & 1.3 & $\begin{array}{c}0.01 / 0.05 / 0.1 / \\
0.5 / 1.0 / 1.3\end{array}$ & 1.3 & \\
\hline$l_{\mathrm{i}}(\mathrm{m})$ & - & 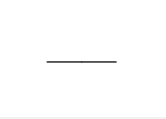 & - & {[} & - & $\begin{array}{c}0.001 / 0.005 / 0.01 / \\
0.02 / 0.04 / 0.08 / 0.16 / \\
0.32 / 0.64 / 1.28\end{array}$ & \\
\hline $\begin{array}{l}l_{w} \\
(\mathrm{~m})\end{array}$ & - & - & - & $\longrightarrow$ & $\longrightarrow$ & $\longrightarrow$ & $\begin{array}{l}0.3 / 0.6 / 0.9 / \\
1.2 / 1.3\end{array}$ \\
\hline$\theta_{0}\left({ }^{\circ}\right)$ & 10 & $\begin{array}{l}30 / 20 / 10 / 0 \\
-10 /-20 /-30\end{array}$ & 10 & 10 & 10 & 10 & \\
\hline$\alpha\left(^{\circ}\right)$ & 17 & 17 & $\begin{array}{l}34 / 17 / \\
0 /-17\end{array}$ & 17 & 17 & 17 & \\
\hline$w$ & 0.05 & 0.05 & 0.05 & $\begin{array}{c}0.025 / 0.05 / 0.075 \\
0.1 / 0.125 / 0.15\end{array}$ & $w / l_{0}=0.1$ & 0.05 & \\
\hline $\begin{array}{c}\Delta t \\
\left({ }^{\circ} \mathrm{C}\right)\end{array}$ & - & - & -5 & -5 & $\begin{array}{l}-1 /-5 /-10 / \\
-15 /-20\end{array}$ & -20 & ـ \\
\hline
\end{tabular}

(a) In the rainy season (late spring or summer), the hydrostatic pressure calculated by Eq. (4) is applied to the water-filled cracks with different lengths $l_{0}$ (case A) and vertical inclinations $\theta_{0}$ (case B), which follows a triangular distribution and its maximum value is given in Table 4 at the crack tip.

(b) In the cool season (autumn or early winter), water-freezing stress owing to frost heave is applied on the surfaces. With a temperature drop of $5{ }^{\circ} \mathrm{C}$ during a single night from $0{ }^{\circ} \mathrm{C}$, its value given by Eq. (6) is $129.6 \mathrm{MPa}$ regardless of how large the vertical inclinations of the rock-free surface $a$ (case

372 C) or crack width $w$ (case D) are. In case E, as shown in Table 5, the freezing stress at different length 373 cracks changes with different temperature drops $(\Delta t)$ during the seasonal alternations. 
cases. Its value on both crack surfaces is nearly the same (38.289 Pa) even in different cases according

to Eq. (10) because the freezing stress is substantially higher than ice gravity in the crack.

Base on case E, we also study crack extension (length) according to Eq. (17). In the calculation, the critical stress $\sigma_{\mathrm{c} 0}$ and $\sigma_{\mathrm{c} 1}$, which determine whether propagation continues or not, is obtained by trial. We first assume a propagation length $\left(\Delta l_{0}\right)$ and calculate the critical stress, and then obtain the calculated extension length using Eq. (17) and compare it with our assumed value. When the extension length given by the formula is consistent with the trial length, it is taken as the solution.

(c) When temperature drops $20{ }^{\circ} \mathrm{C}$ from $0{ }^{\circ} \mathrm{C}$ during autumn, the water gradually freezes and different lengths of frozen ice $\left(l_{i}\right)$ form in the crack of case $\mathrm{F}$. In this case, the freezing stress remains at 198.2 MPa and the water pressure changes according to Eqs. (6) to (7), as listed in Table 6.

In case $G$, the ice melts gradually in spring. Except for the hydrostatic pressure, stress induced by gravity of the unmelted ice $\left(l_{i}\right)$ calculated by Eqs. (1) to (5) is also generated, as listed in Table 6 .

$$
\text { The average static friction coefficient in our calculation model between rock and ice is given as }
$$

0.45 according to laboratory tests and literature values (Mamot et al. 2018), without considering its change with temperature or pressure.

\subsection{Simulation on the dynamic evolution of crack extension and investigation of the collapse mechanism during different seasons}

In the freeze-thaw zone of the eastern Sichuan-Tibet Mountains, the crack temperature is directly determined by surrounding air temperature and fluctuates dramatically with the seasons, resulting in the phase change of water in the crack and the breaks of the fractured rocks. Hence, the seasonal fluctuation of temperature needs to be considered in collapse simulation. Based on the local meteorological data given in Table 1, a temperature change series (Table 7) is adopted to calculate the crack propagation in a realistic perilous rock at an altitude of $3800 \mathrm{~m}$ in Fig. 11(c), and show the collapse mechanism in the freeze-thaw zone. 
401 The hydrostatic pressure on the tip of different lengths $\left(l_{0}\right.$, case A) and vertical inclinations $\left(\theta_{0}\right.$, case B) crack

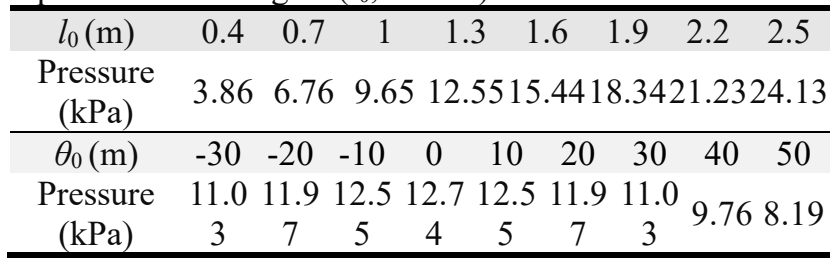

402 Table 5

403 Freezing stress applied on the internal surfaces of different cracks with different temperature drops (case E)

404

405

406

407

408

\section{Table 7}

\begin{tabular}{cccccc}
\hline Temperature $\left({ }^{\circ} \mathrm{C}\right)$ & -1 & -5 & -10 & -15 & -20 \\
$\Delta t\left({ }^{\circ} \mathrm{C}\right)$ & 1 & 5 & 10 & 15 & 20 \\
\hline Pressure $(\mathrm{MPa})$ & 113.7 & 129.6 & 150.9 & 173.7 & 198.0 \\
\hline
\end{tabular}

\section{Table 6}

Stress applied on internal surfaces of cracks with different lengths of frozen ice in autumn or unmelt ice in spring (case $\mathrm{F}$ and case G)

\begin{tabular}{ccccc}
\hline Case $\mathrm{F}$ freeing process & \multicolumn{3}{c}{ Case G melting process } \\
\hline $\begin{array}{c}l_{i} \\
(\mathrm{~m})\end{array}$ & $\begin{array}{c}\text { Maximum } \\
\text { hydrostatic } \\
\text { pressure }(\mathrm{kPa})\end{array}$ & $\begin{array}{c}l_{i} \\
(\mathrm{~m})\end{array}$ & $\begin{array}{c}\text { Maximum } \\
\text { hydrostatic } \\
\text { pressure }(\mathrm{kPa})\end{array}$ & $\begin{array}{c}p_{\text {tip }} \\
(\mathrm{kPa})\end{array}$ \\
\hline 0.01 & 12.64 & 1.3 & - & 11.09 \\
0.02 & 12.54 & 1.0 & 2.94 & 11.47 \\
0.04 & 12.35 & 0.7 & 5.88 & 11.85 \\
0.08 & 11.96 & 0.4 & 8.82 & 12.23 \\
0.16 & 11.17 & 0.1 & 11.76 & 12.61 \\
0.32 & 9.60 & 0 & 12.74 & - \\
\hline
\end{tabular}

Temperature changes at an engineering point $(3800 \mathrm{~m})$ over a year.

Cold winterWarm springHot summerCool autumnCold winter Monthly average temperature $\left({ }^{\circ} \mathrm{C}\right) \quad \mathbf{- 1 7 . 6} \quad-6.3$ 4.8 $-17.6$

\section{Results and discussion}

\subsection{Fracture mechanism of rock collapse induced by the hydrostatic pressure of crack water in} rainy seasons

In late spring or hot summer, the ice in cracks of perilous rocks completely melts and the abundant

413 seasonal rainfall leads the hydrostatic pressure to dominate the initiation and propagation of such deep

414 cracks, which leads to collapse events on mountains. In this subsection, we systematically study the

415 influence of length (case A) and vertical inclination (case B) of a crack on the fracture characteristics 416 of perilous rocks under gravity and the hydrostatic pressure (Table 4).

417 Fig. 13(a) depicts the variation of SIFs with crack length. It is clear that a longer crack counts 418 against the stability of the crack. There exists a critical value of crack length $l_{c}$ that induce the 419 propagation starts, which is $5.75 \mathrm{~m}$. Hence the scale of collapse induced by rainfall in summer can be several meters. Because our model ignores the influence of mechanical property deterioration of 
421 perilous rock during rainfall, the calculated result is slightly larger but nearly agrees with our field study, as discussed in subsection 2.3.
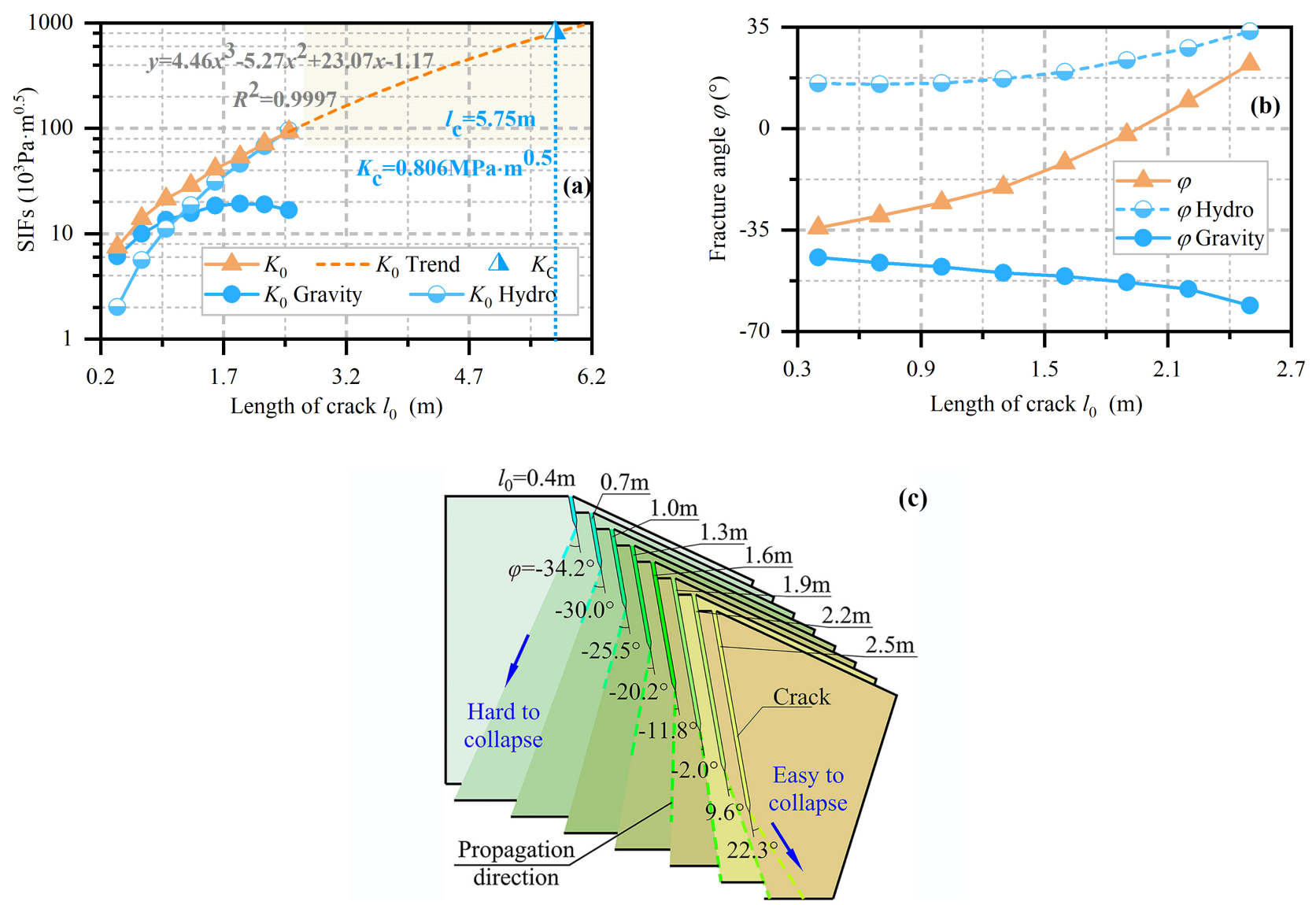

Fig. 13 Influence of the crack length on (a) $K_{0}$ and its contributions (b) fracture angle, and (c) propagation (case A). The suffixes (Gravity, Hydro) are used to mark the load conditions under rock gravity and hydrostatic pressure, respectively.

Comparing with the contribution of gravity terms to the SIF values, the effect of hydrostatic pressure is increasingly significant with increasing crack length. This can be expected because the gravity does not change with crack length but hydrostatic pressure loading does, which also can be verified by the change of fracture angle in Fig. 13(b).

We also can observe how a crack propagates with a mixed-mode considering both hydrostatic 432 pressure and gravity loading in Fig. 13(b). Obviously, the crack propagation angle, which ranges from $433-34.2^{\circ}$ to $22.3^{\circ}$, is close to the contribution from gravity at first and then gradually tends to that of 434 gravity with the increased crack length. More importantly, as shown in Fig. 13(c), compared with a 435 shorter water-filled crack, the propagation of a longer one is more toward the outside of the slope and 
facilitates collapse.
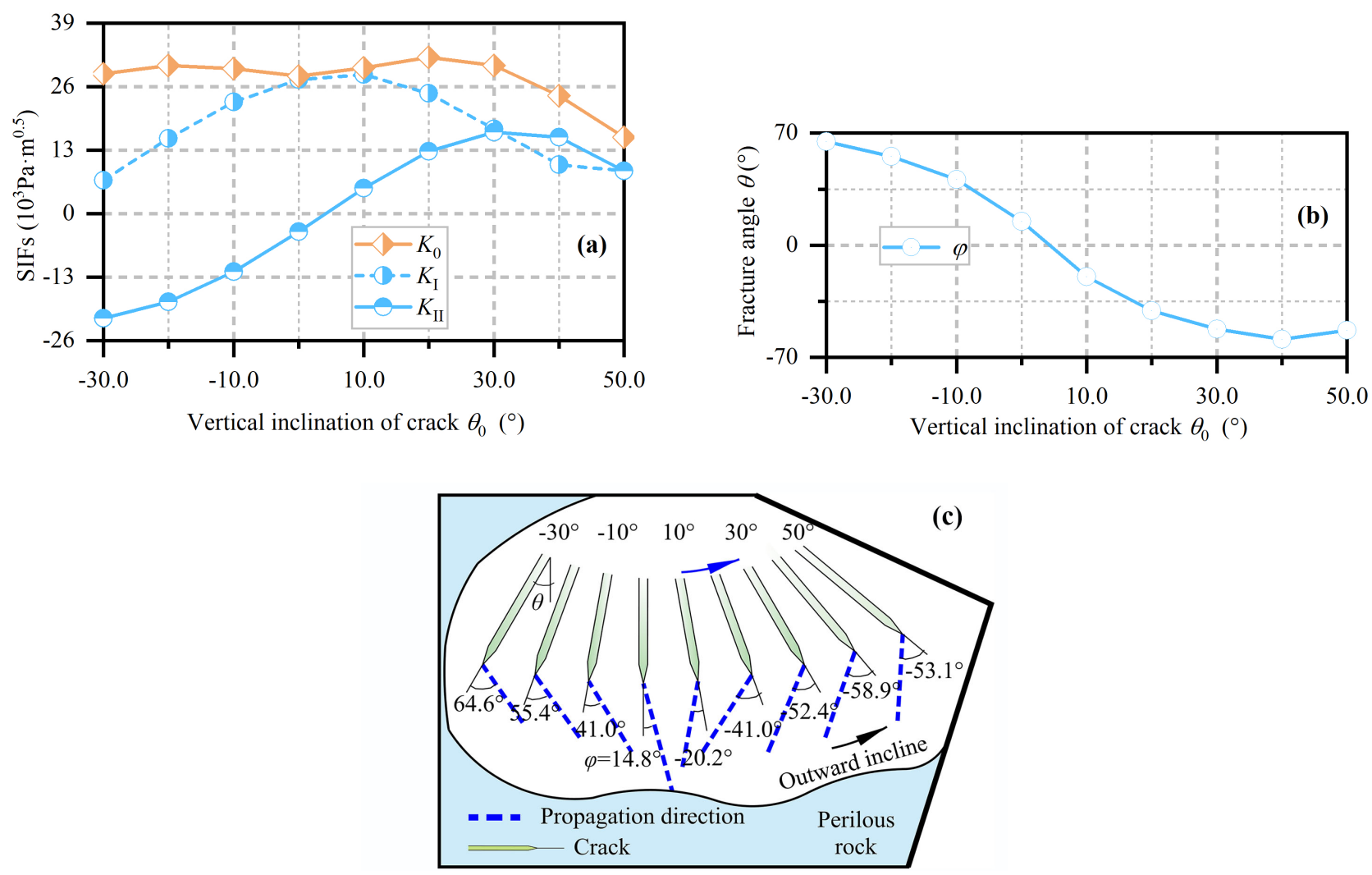

Fig. 14 Change of (a) compound SIF $K_{0}, K_{\mathrm{I}}$ and $K_{\mathrm{II}}$, (b) fracture angle, and (c) crack propagation direction with the vertical inclination of crack (case B).

Apart from crack length, crack inclination also strongly affects the fracture character. For a vertical

crack $\left(\theta_{0}=0\right)$ in Fig. 14(a), $K_{\mathrm{I}}$ achieves its highest value whereas $K_{\mathrm{II}}$ is nearly zero, which indicates

443 the fracture follows a purely tensile mode. However, as the crack tends inward $\left(\theta_{0}<0\right)$ or outward $\left(\theta_{0}>\right.$

$4440), K_{\text {II }}$ increases, which implies that the role of hydrostatic pressure dominates at low crack angles but 445 is gradually replaced by rock gravity as the angle increases.

446 The highest compound SIF $K_{0}$, which indicates the most unstable scenario, appears at a fracture 447 angle of $20^{\circ}$. A. negative related fracture angle in Fig. 14(b) will result in larger rock mass collapse, as 448 illustrated in Fig. 14(c). However, in this case, the propagation requires more energy owing to its 449 inward direction (i.e., toward the inner slope).

$450 \quad$ In late spring or summer, fractured rocks with longer and modest outward-inclined cracks are more 
451 prone to serious collapse during rainfall. The critical crack length is typically no less than several 452 meters, which indicates a large volume collapse of perilous rocks unless collapse cannot occur under 453 abundant rainfall.

\section{$454 \quad 6.2$ Fracture mechanism of rock collapse induced by freezing stress on a fully ice-filled crack 455 during cooling seasons}

456 In autumn or early winter, freezing stress is generated on a crack face when the water begins to 457 freeze with decreasing temperature, which becomes a new dominant factor that determines whether a 458 crack will propagate and if a collapse will occur. In this subsection, by considering the stress driving 459 crack evolution such as freezing stresses (section 5.2 (b), Table 5) and gravity, the effects of vertical 460 inclination of the rock-free face (case C), crack width (case D), and different temperature drops (case

E) on the fracture characteristics were studied systematically.
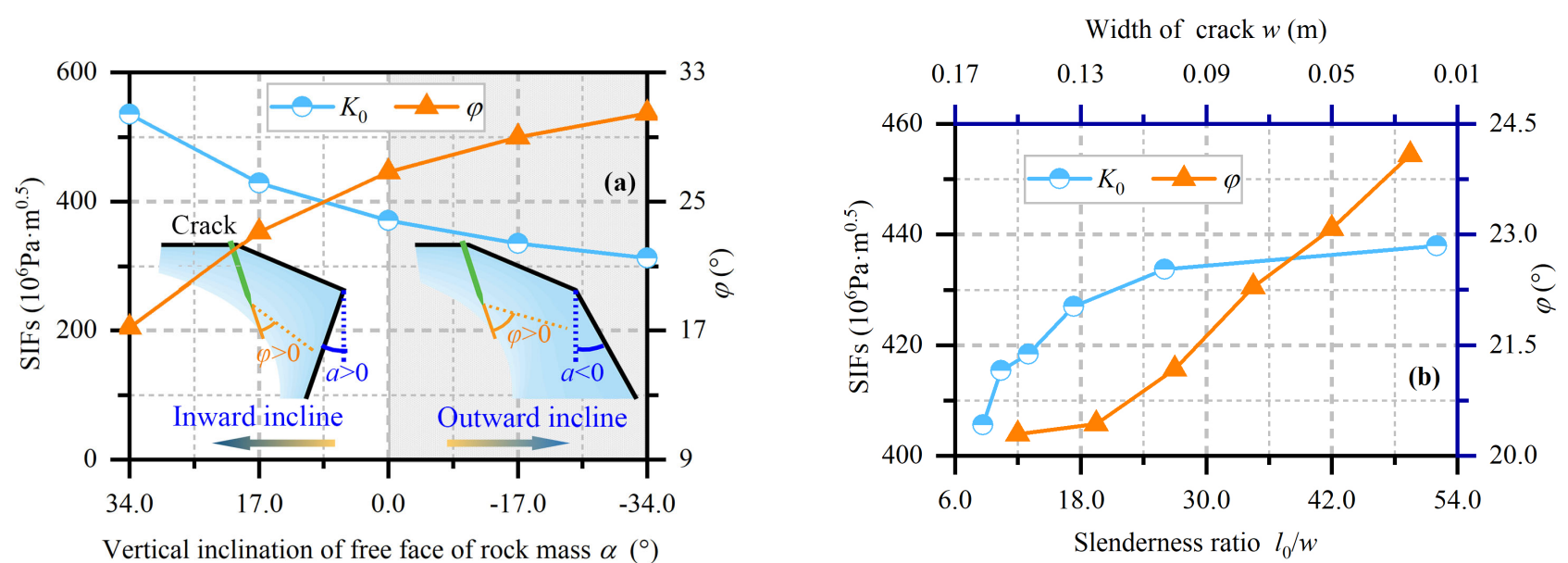

frozen crack. The compound SIF $K_{0}$ declines quickly with a reduction of $a$ from positive to negative, indicating that the slope with an inward-inclined face $(a>0)$ is more prone to fail than one with an outward face $(a<0)$. The fracture angle $(\varphi)$ remains positive and is beneficial to collapse during this entire process. 
a smaller slenderness ratio has a smaller value of $K_{0}$ and $\varphi$ and is comparatively stable.

472 of magnitude bigger than those for the water-filled crack in rainy seasons. The critical length calculated

473 for a crack under freezing stress in case $\mathrm{E}$ is only $0.016 \mathrm{~m}$, which is substantially smaller than that 474 given in a water-filled crack in Fig. 13(a), which indicates that collapses caused by freezing stress would be very minor most of the time compared with rainfall-induced collapses in summer.
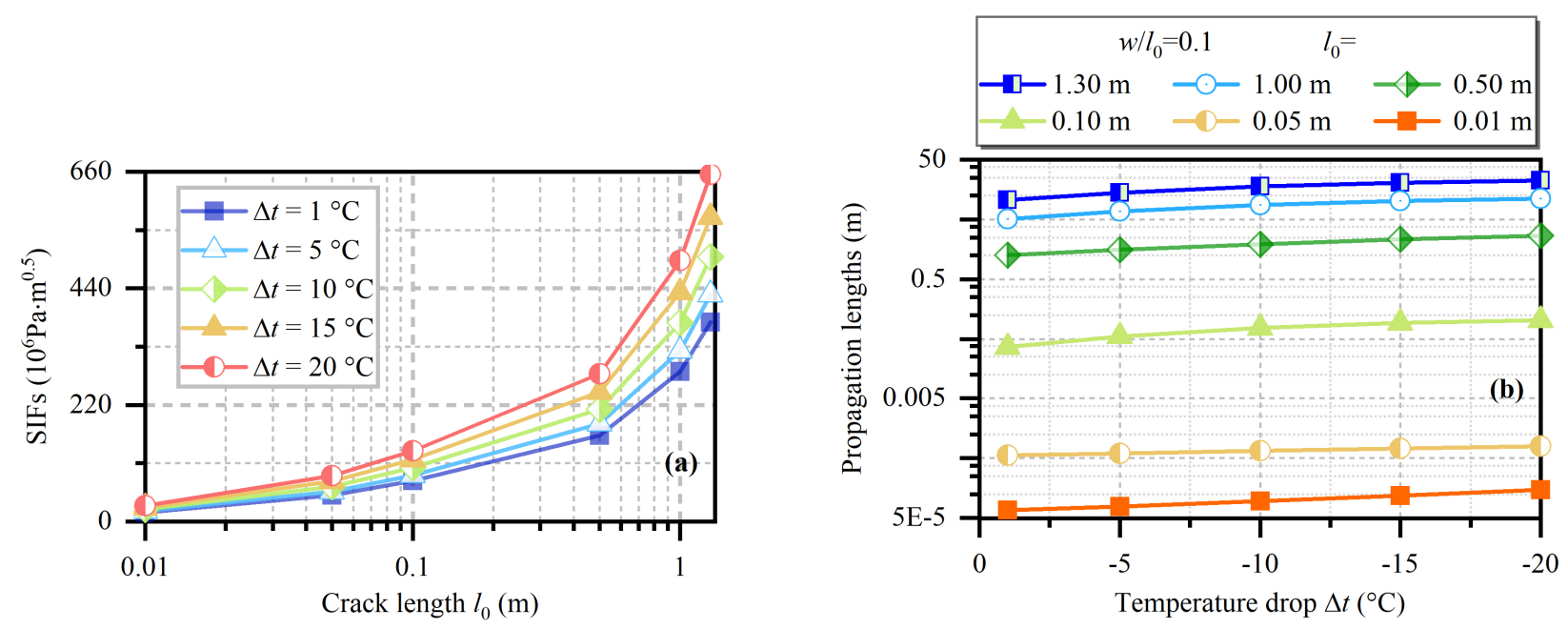

Fig. 16 Effect of crack length and temperature drop $\Delta t$ on (a) SIFs and (b) propagation length (case E)

Fig. 16(a) shows the effect of a temperature drop on SIFs when the crack is frozen in autumn. It

can be easily concluded that larger $\Delta t$ from $0{ }^{\circ} \mathrm{C}$ are associated with higher SIFs at the tip, regardless of length of the ice-filled crack. Hence, a continuous, sharp, wide-range cooling process could lead to

a large-scale but minor collapse of saturated-fractured rocks, such as freeze-thaw weathering in mountains, which explains the character of collapse accumulation and agrees well with our field study discussed in subsection 3.3.

We also study the crack propagation length with different temperature drops $(\Delta t)$ according to Eqs. (12-14). Fig. 16(b) shows clearly that extension increases for all length cracks in case E when the temperature drop is bigger, which further confirms that minor collapses (freeze-thaw weathering) are more likely to occur during rapidly cooling weather, such as cold waves.

An important detail to mention is the temperature drop and freezing stress may more strongly affect 
the propagation length for a longer crack. As shown Fig. 16(b), the extension increases by no less than

490 five orders of magnitude while the original length of crack varies from 0.01 to $1.3 \mathrm{~m}$, which indicates

491 that propagation during continuous several freeze-thaw cycles is an accelerated process and that longer

492 cracks become longer. This well explains why fractured rocks containing deep cracks can develop 493 comparatively quickly and are prone to collapse.

494 In autumn or early winter, longer-thinner ice-filled cracks can easily crack under abrupt 495 temperature drops and lead to fracturing, especially for rocks with an inward-inclined face collapse.

496 The freezing stress is so huge that leads to a tiny critical length, which means nearly all visible cracks 497 in nature can be frozen to propagate and cause small collapses easily, like erosion. \\ 6.3 Fracture characteristics of cracks filled with different lengths of frozen ice in autumn or meltwater in spring}

The natural variation of temperature is not instantaneous and the freezing/melting of water in cracks is a progressive process. In this subsection, considering the different stresses during the freezing or melting process (Table 6, section 5.2 (c)) and the gravity, the effect of frozen ice length (case F) and meltwater length (case G) on the fracture characteristics was studied systematically.
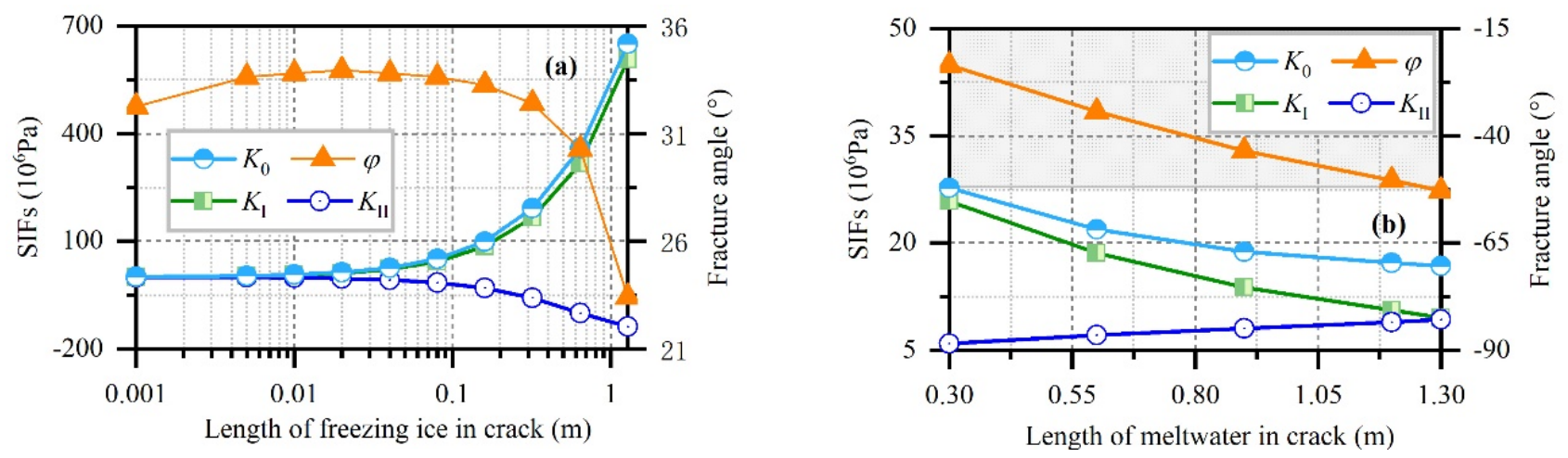

Fig. 17 Variation of $\varphi, K_{0}, K_{\mathrm{I}}$, and $K_{\mathrm{II}}$ with the length of (a) freezing ice in autumn and (b) meltwater in spring.

with the ice length increment during crack freezing in autumn. This indicates more complete freezing during a rapid cooling process, which implies that longer ice in cracks can more easily cause collapse.

Note that the compound SIF $K_{0}$ is very close to its individual mode $K_{\mathrm{I}}$ but not $K_{\mathrm{II}}$, which means 
that freezing stress dominates the cracking. It can be inferred that a purely tensile fracturing mode may nearly occur when the frozen ice in a crack is sufficiently long. For example, the fracture angle declines

512 sharply when the frozen ice is longer than $0.1 \mathrm{~m}$ in Fig. 17(a).

As shown in Fig. 17(b), longer meltwater in a crack is associated with smaller SIFs. Obviously, without considering the softening effect of saturated rock, the stress induced by ice gravity rather than

515 hydrostatic pressure is easily sufficient to split a crack. Moreover, the absolute value of a fracture angle 516 increases when the crack ice melts, indicating the mixed-mode of crack changes gradually from the 517 purely tensile fracturing mode to the purely shear fracturing mode.

518 In summary, as the temperature continually drops in autumn, cracks extend more easily with the 519 frozen ice growing within them. When the ice melts in warm spring, the crack tends to be stable if not 520 considering the rainfall supply and rock softening.

\subsection{Dynamic evolution of crack extension and collapse mechanism}

Realistic fracture models (Fig. 11c) were studied to determine the collapse mechanism of fractured rocks during different seasons in the eastern Sichuan-Tibet Mountains. The load conditions are given by the models in section 3 with temperature data in Table 7.

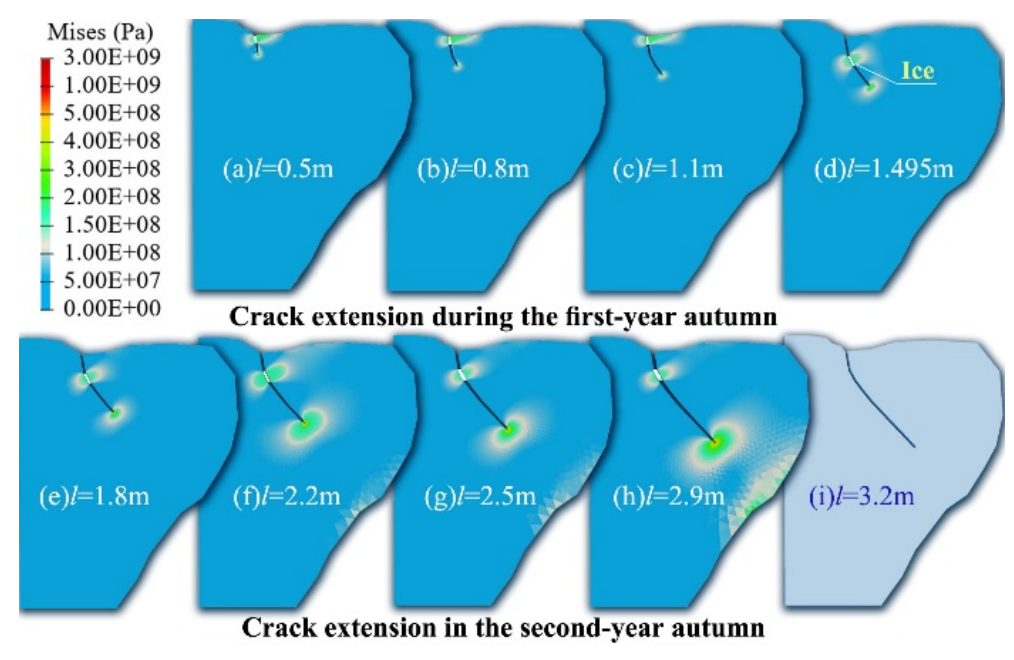

Fig. 18 Evolution of crack path and stress contours of perilous rocks during the first (a-d) and second (e-i) autumn.

(d) The final pattern of crack at the end of the first autumn and the initial stress state at the beginning of the second 
As shown in Fig. 18, the original crack is 0.5 -m long and full of water. In autumn of the first year, 530 only the upper $0.2 \mathrm{~m}$ of water is frozen. The calculation reveals that when the temperature drops $53117.6^{\circ} \mathrm{C}$ below zero, the freezing stress and friction on the crack face reach $186 \mathrm{MPa}$ and $217.15 \mathrm{~Pa}$, 532 respectively, which directly causes the crack to propagate. Figs. 18(a) to (d) show that stress 533 concentrates at the crack tip and causes $0.995 \mathrm{~m}$ of propagation under freezing stress during the first 534 autumn. Note that although the crack grows to $1.495 \mathrm{~m}$, it does not meet the critical length and 535 continues to extend in the following winter, spring, and summer.

536 Propagation occurs again when autumn returns in the second year. As shown in Fig. 18(d), the new 537 crack is almost full of water except for $0.5 \mathrm{~m}$ in the upper section. When the temperature drops from 538 zero to $-17.6{ }^{\circ} \mathrm{C}$, about $0.3 \mathrm{~m}$ of ice forms. As shown in Figs. $18(\mathrm{e})$ to (i), the crack propagates along 539 nearly a straight line and extends $1.705 \mathrm{~m}$ with mode I, which differs from the counterclockwise 540 propagation at the beginning of the first-year autumn, indicating the overwhelming influence of 541 freezing stress when the crack grows longer. When propagation terminates at the end of the temperature 542 drop in second-year winter, the final crack length in Fig 18(i) is $3.2 \mathrm{~m}$.
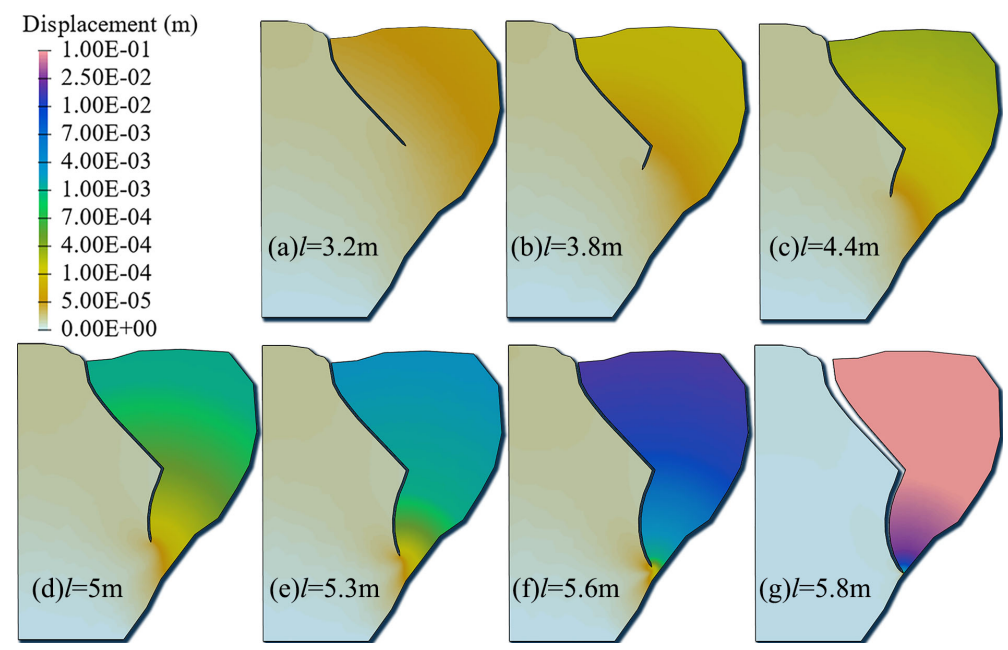

Fig. 19 Crack propagation under hydrostatic pressure in the summer of the third year and the dynamic evolution of the collapse process.

Due to crack growth in the past 2 years, the rock damage is aggravated and the influence of gravity is enhanced. The calculation shows that the critical crack length decreases to $3.05 \mathrm{~m}$ under hydrostatic 
stress. Hence, in the third-year spring and autumn when the ice melts and precipitation is abundant,

549 the crack fills with water and begins to propagate again. As shown in Fig. 19, the crack initially 550 propagates clockwise with a fracture angle of $-62.2^{\circ}$, which differs substantially from the propagation 551 direction under freezing stress in the previous 2 years. But the trend reverses with later crack growth 552 mainly because hydrostatic pressure dominates the fracture. During the final stage, when the crack 553 extends to $5.8 \mathrm{~m}$, deformation increases sharply from Fig. 19(f) to (g) and collapse eventually occurs. 554 In brief, the collapse of fractured rocks in different seasons is the result of initiation, propagation, 555 and connection of a primary crack under the fluctuation of water-heat combinations. During this 556 process, freezing stress in the cooling seasons is the major driving force that weathers, breaks, and 557 ultimately destroys a fractured rock with any length cracks, which is as a precondition and first step to 558 collapse. While hydrostatic pressure in the rainy season exerts more of a promoting factor on long 559 cracks with sufficiently small critical length and can directly lead to collapse. Rock damage 560 accumulation due to crack growth can rapidly reduce stability and lead to collapse.

\section{Conclusions}

A theoretical model of different stresses that drive fracture propagation corresponding to different seasons is proposed based on a field investigation. According to these models, SIFs, fracture angle, and extension are calculated by the fracture mechanics, and the effects of crack characteristics under the seasonal combination of water-heat on crack stability and rock collapse patterns are analyzed. With the help of XFEM, the propagation of the crack is simulated to explain the rock collapse mechanism by applying new theory into practical examples. Some conclusions are obtained as follows:

1) Owing to the fluctuation of water-heat combination during different seasons, freezing stress and crack evolution in cooling and rainy seasons, respectively.

2) Freezing stress dominates whereas hydrostatic stress is relatively small. The critical length of a 
frozen crack is thus substantially smaller than that of a water-filled crack.

3) Almost any longer crack in a natural perilous rock can easily fracture under freezing stress,

574 which mostly results in more frequent, wide-spread, and small-scale collapses (i.e., rock disintegration)

575 during cooling seasons, although some large collapses can also occur. On the contrary, owing to the 576 large critical length, only a few sufficiently long cracks can propagate under hydrostatic pressure, 577 which causes collapse in rainy seasons to become volumetrically larger.

4) The extension length of a frozen crack is relatively stable during one continuous cooling process, 579 whereas crack extension during abundant rainfall continues until collapse.

5) Freezing stress in the cooling season is the major driving force that weathers, breaks, and destroys fractured rock with cracks of any length, which is a precondition and first step to collapse.

582 Hydrostatic pressure in the rainy season plays more of a role in promoting long cracks that have a critical length, and can directly lead to collapse.

6) In general, fractured rocks with longer and modest outward-inclined cracks are more prone to serious collapse during rainfall in late spring or summer. In autumn or early winter, longer and thinner ice-filled cracks more easily crack under the sharp drop of temperature and cause fractured rocks, especially those with inward-inclined faces, to undergo serious collapse.

7) As the temperature continually decreases in autumn, cracks become easier to extend with frozen rainfall supply and rock softening are not considered.

8) The collapse of fractured rocks in different seasons is the result of initiation, propagation, and 593 process of rock damage accumulation owing to crack growth under fluctuating combinations of water 594 and heat.

\section{Declaration of competing interest}


The authors declare that they have no known competing financial interests or personal relationships

that could have appeared to influence the work reported in this paper.

\section{Acknowledgments}

Funding for this work was provided through the National Key R\&D Program of China 600 (2018YFC1505003-5) and the National Natural Science Foundation of China (41877291, 41672356). 601 We thank Esther Posner, PhD, from Liwen Bianji, Edanz Editing China (www.liwenbianji.cn/ac), for editing the English text of a draft of this manuscript.

\section{Reference}

Alippi C, Camplani R, Galperti C, Marullo A, Roveri M (2010) An hybrid wireless-wired monitoring system for real-time rock collapse forecasting. The 7th IEEE International Conference on Mobile Ad-hoc and Sensor Systems (IEEE MASS 2010). pp 224-231

Backers T, Stephansson O (2012) ISRM Suggested Method for the Determination of Mode II Fracture Toughness. Rock Mechanics and Rock Engineering 45:1011-1022. http://doi.org/10.1007/s00603-012-0271-9

Bassis JN, Walker CC (2011) Upper and lower limits on the stability of calving glaciers from the yield strength envelope of ice. Proceedings of the Royal Society A: Mathematical, Physical and Engineering Sciences 468:913-931. http://doi.org/10.1098/rspa.2011.0422

Chen H, Tang H, He X (2012) Stability analysis of perilous rock in views of damage and fracture mechanics. Advanced Materials Research 455-456:1561-1566. http://doi.org/10.4028/www.scientific.net/AMR.455-456.1561

Dramis F, Govi M, Guglielmin M, Mortara G (1995) Mountain permafrost and slope instability in the Italian Alps. The Val Pola Landslide. Permafrost and Periglacial Processes 6:73-81. http://doi.org/10.1002/ppp.3430060108

Du M, Liu J, Zhang X, Li Y, Tang Y (2017) Spatial distributions of surface-air-temperature on the Tibetan Plateau and its recent change. International Journal of Energy and Environmental Engineering 11:89-93

Eisbacher GH (1979) Cliff collapse and rock avalanches (sturzstroms) in the Mackenzie Mountains, northwestern Canada. Canadian Geotechnical Journal 16:309-334. http://doi.org/10.1139/t79-032

Erdogan F, Sih GC (1963) On the Crack Extension in Plates Under Plane Loading and Transverse Shear. Journal of Basic Engineering 85:519-525. http://doi.org/10.1115/1.3656897

Ez Eldin MAM, Tang H, Xu Y, Xiong C, Ge Y (2013) Engineering geological and geophysical assessment of the 2009 Jiwei Shan rockslide, Wulong, China. Open Journal of Geology 3 60-70. http://doi.org/10.4236/ojg.2013.32B014

Fowell RJ, Hudson JA, Xu C, Chen JF (1995) Suggested Method for Determining Mode-I Fracture-Toughness Using Cracked Chevron-Notched Brazilian Disc (Ccnbd) Specimens. International Journal of Rock Mechanics and Mining Sciences \& Geomechanics Abstracts 32:57-64. http://doi.org/10.1016/0148-9062(95)92395-X 
Griffith AA (1921) The Phenomena of Rupture and Flow in Solids. Philosophical Transactions of the Royal Society of http://doi.org/10.1098/rsta.1921.0006

Hallet B (2006) Geology. Why do freezing rocks break? Science 314:1092-1093. http://doi.org/10.1126/science.1135200

Hore K, Kelman I, Mercer J, Gaillard JC (2018) Climate change and disasters. In: Rodríguez H, Donner W, Trainor JE (eds). Handbook of Disaster Research. Springer International Publishing, Cham. pp 145-159

Hu KH, Wu CH, Tang JB, Pasuto A, Li YJ, Yan SX (2018) New understandings of the June 24th 2017 Xinmo Landslide, Maoxian, Sichuan, China. Landslides 15:2465-2474. http://doi.org/10.1007/s10346-018-1073-2

Locat P, Couture R, Leroueil S, Locat J, Jaboyedoff M (2006) Fragmentation energy in rock avalanches. Canadian Geotechnical Journal 43:830-851. http://doi.org/10.1139/t06-045

Mamot P, Weber S, Schröder T, Krautblatter M (2018) A temperature- and stress-controlled failure criterion for ice-filled permafrost rock joints. The Cryosphere 12:3333-3353. http://doi.org/10.5194/tc-12-3333-2018

McCarthy C, Savage H, Nettles M (2017) Temperature dependence of ice-on-rock friction at realistic glacier conditions. Philos Trans A Math Phys Eng Sci 375. http://doi.org/10.1098/rsta.2015.0348

Neaupane KM, Yamabe T (2001) A fully coupled thermo-hydro-mechanical nonlinear model for a frozen medium. Computers and Geotechnics 28:613-637. http://doi.org/10.1016/S0266-352x(01)00015-5

Nicholson DT, Nicholson FH (2000) Physical deterioration of sedimentary rocks subjected to experimental freeze-thaw weathering. Earth Surface Processes and Landforms 25:1295-1307. http://doi.org/10.1002/10969837(200011)25:12<1295::Aid-esp138>3.0.Co;2-e

Panek T, Hradecky J, Silhan K, Smolkova V, Altova V (2009) Time constraints for the evolution of a large slope collapse in karstified mountainous terrain of the southwestern Crimean Mountains, Ukraine. Geomorphology 108:171-181. http://doi.org/10.1016/j.geomorph.2009.01.003

Wang Y, Waisman H (2018) An arc-length method for controlled cohesive crack propagation using high-order XFEM and Irwin's crack closure integral. Engineering Fracture Mechanics 199:235-256. http://doi.org/10.1016/j.engfracmech.2018.05.018

Wu Y, Wang Y, Haim W, He S, Li X (2020) Fracture of rocks in the mountains of Southeast Tibet under hydrothermal conditions at different elevations. Bulletin of Engineering Geology and the Environment 79:4291-4308. http://doi.org/10.1007/s10064-020-01806-x

Xu Q, Shang Y, van Asch T, Wang S, Zhang Z, Dong X (2012) Observations from the large, rapid Yigong rock slide 659 


\section{Figures}

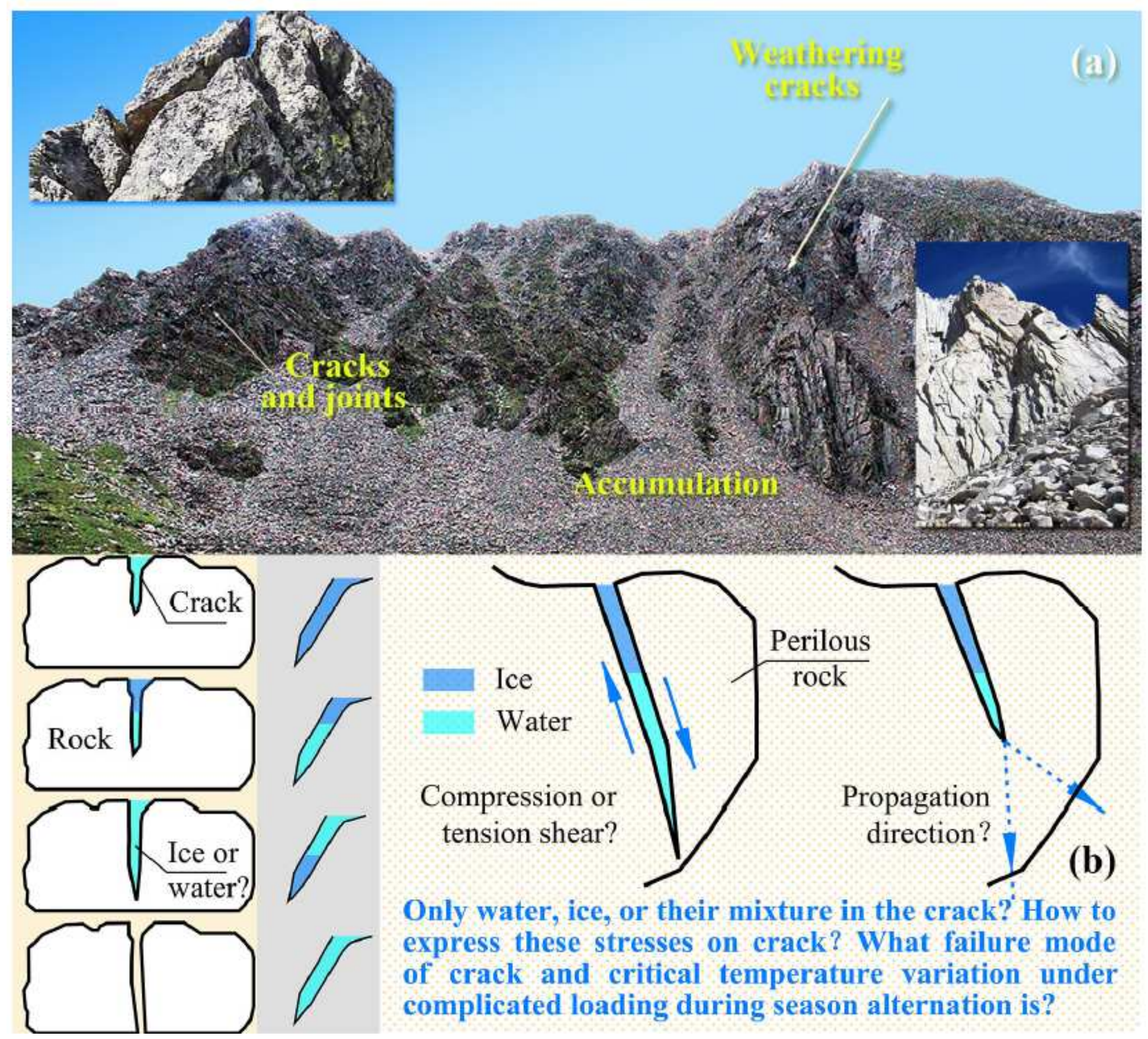

Figure 1

Collapse bodies, perilous rock, and cracks in the mountains 


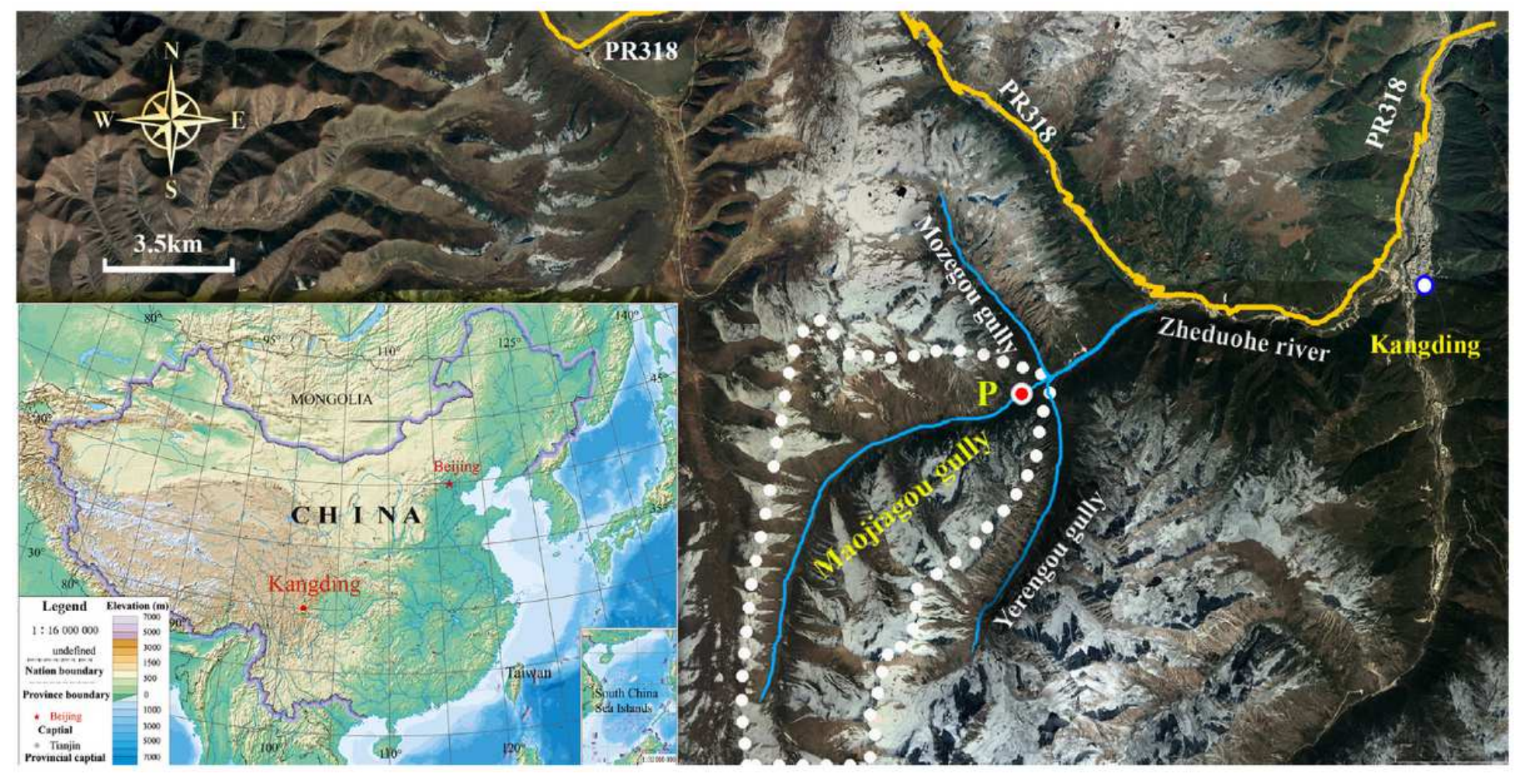

Figure 2

The location of the study point. Note: The designations employed and the presentation of the material on this map do not imply the expression of any opinion whatsoever on the part of Research Square concerning the legal status of any country, territory, city or area or of its authorities, or concerning the delimitation of its frontiers or boundaries. This map has been provided by the authors. 



Figure 3

Collapses in Maojiagou gully and the character of their deposits

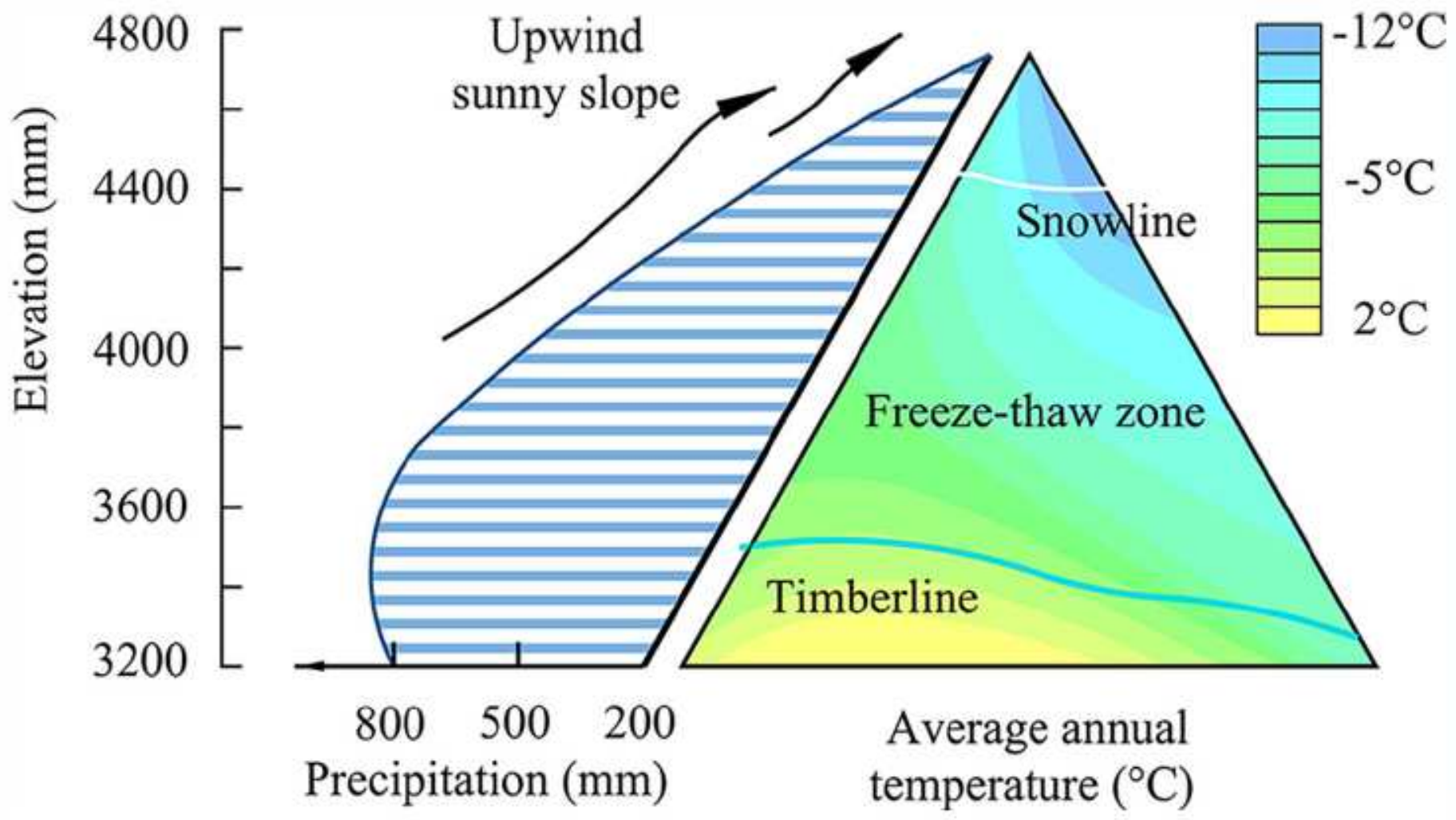


Figure 4

Sketch of water-heat combination in mountains of the study area.

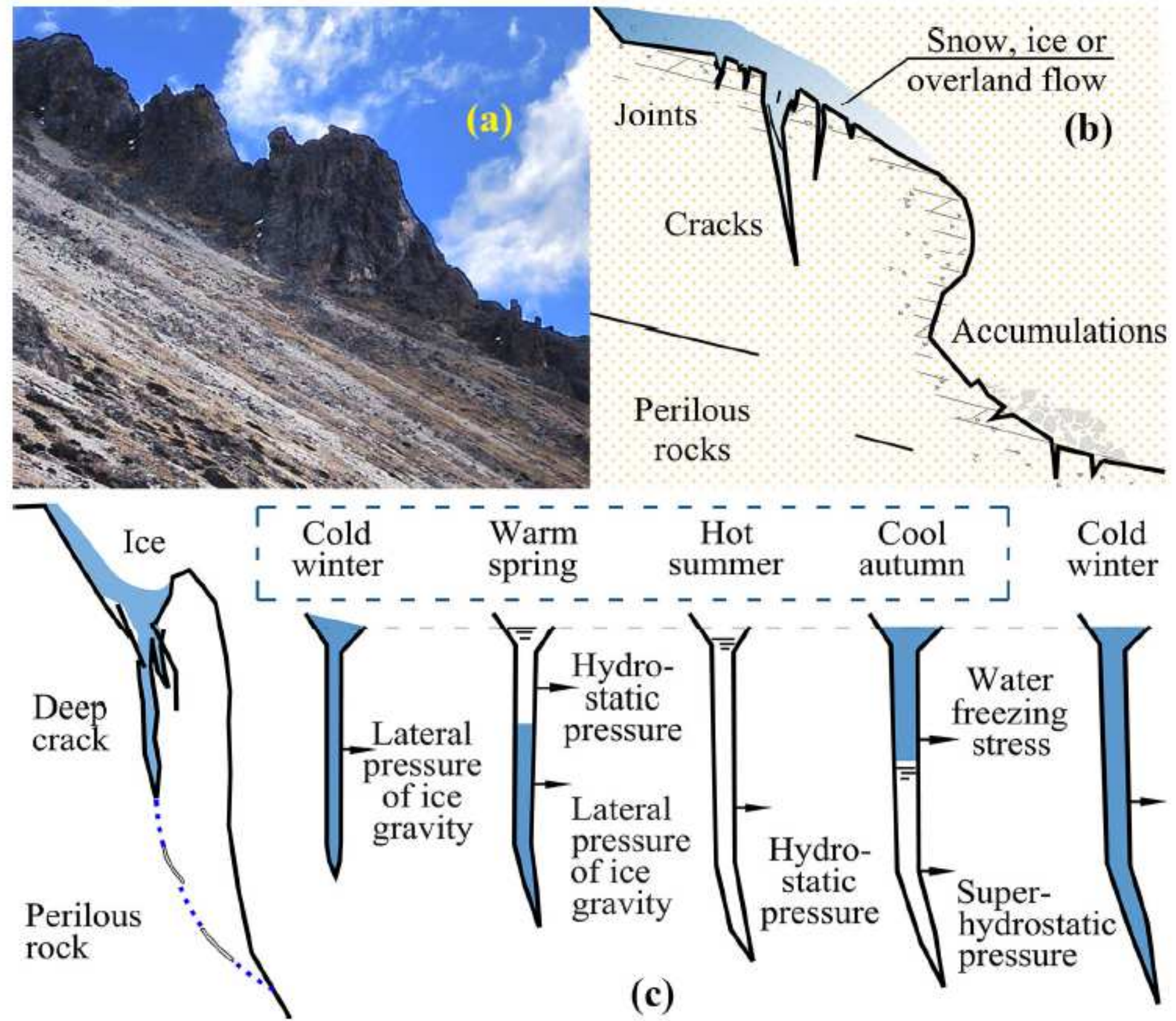

Figure 5

Idealized schematic diagram of (a-b) perilous rock and (c) the cracking process in different seasons 

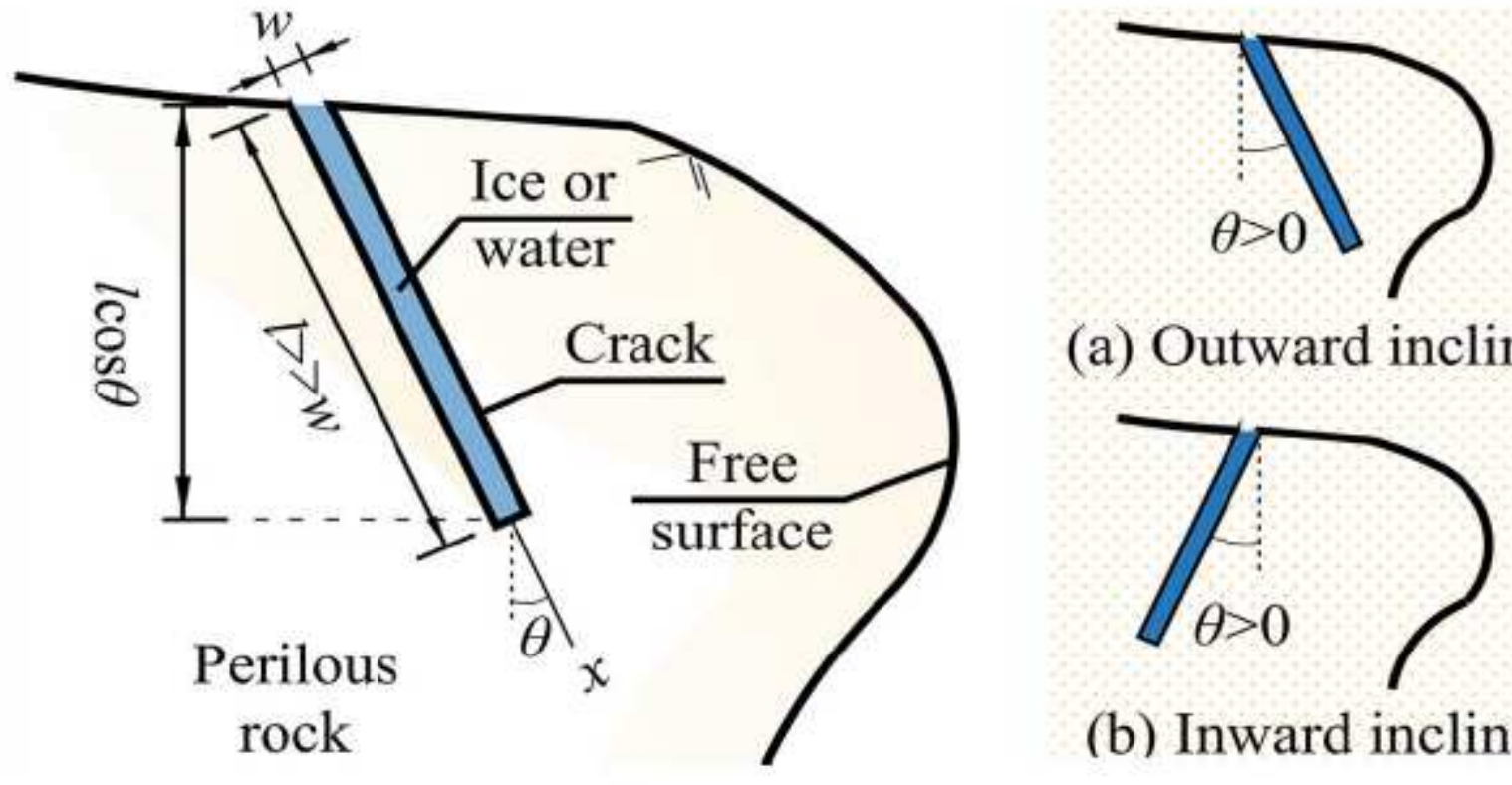

(a) Outward incline

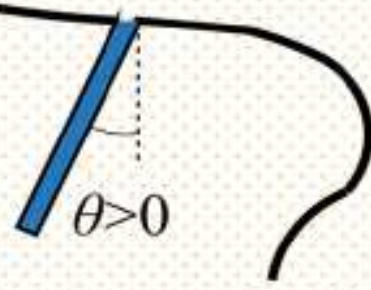

(b) Inward incline

Figure 6

Model for crack propagation in perilous rocks. Note the angle $\theta$ is positive when the crack inclines outward.

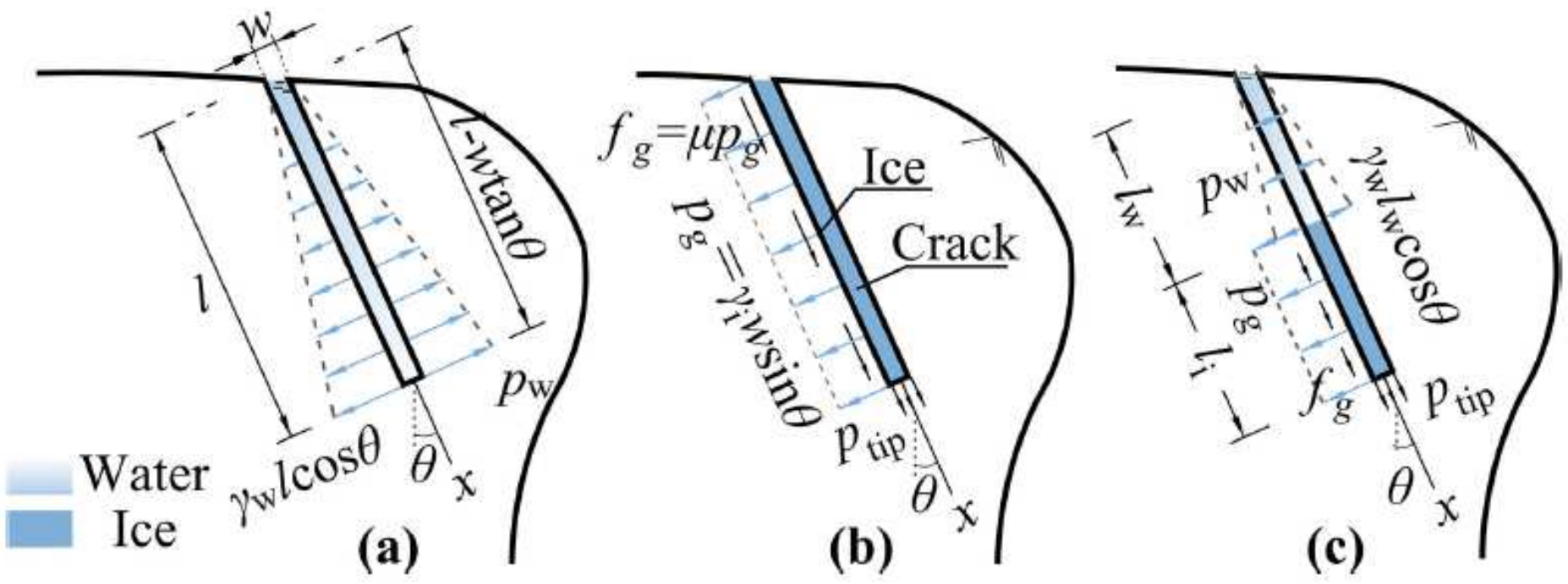

Figure 7

Stress on the surface (a) of a water-filled crack in summer, (b) of an ice-filled crack in winter, and (c) when the ice melts with increasing temperature in spring 

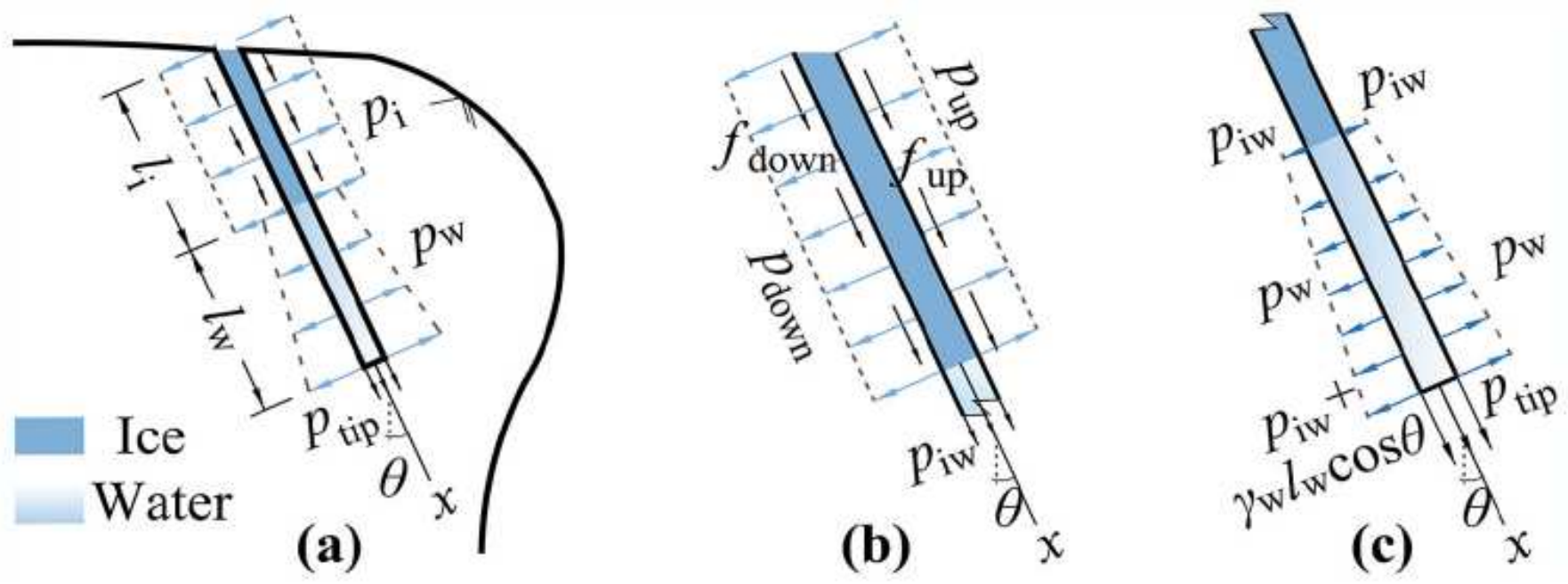

Figure 8

Stress on ice-water-filled crack when the temperature drops in cool autumn

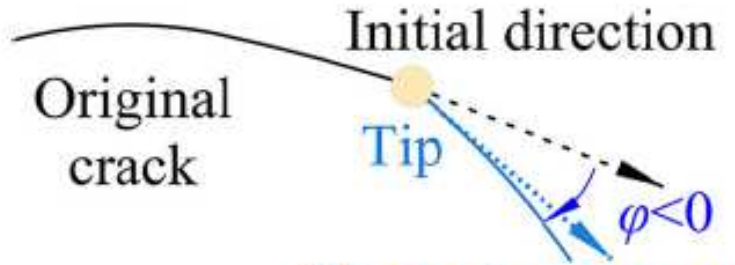

Clockwise propagation

(a)

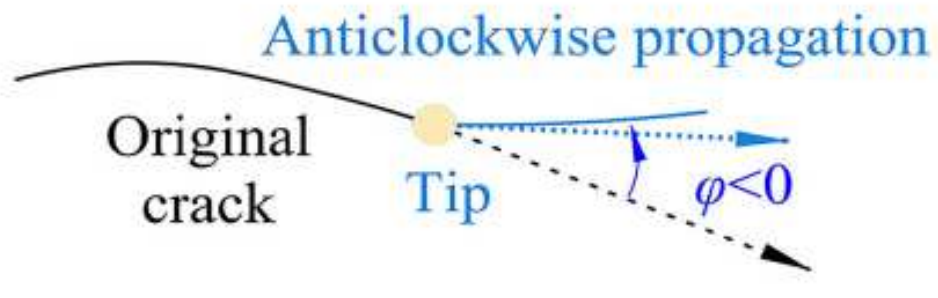

Initial direction

(b)

Figure 9

Schematic diagram of the crack propagation direction
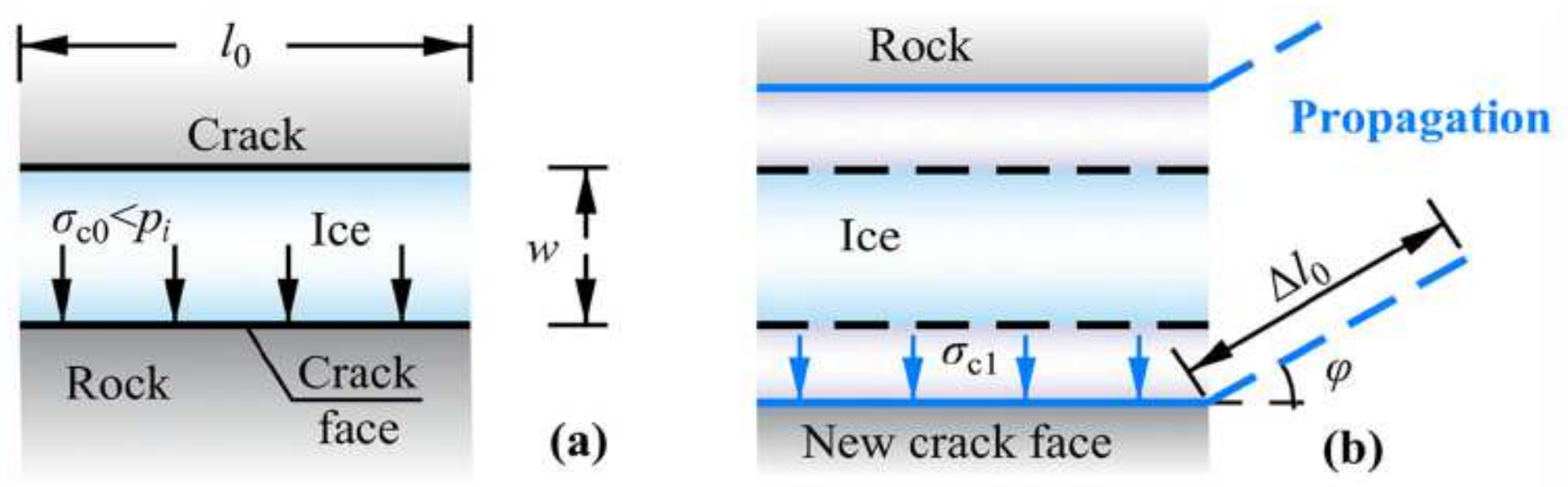
Figure 10

Calculation sketch of the crack propagation length

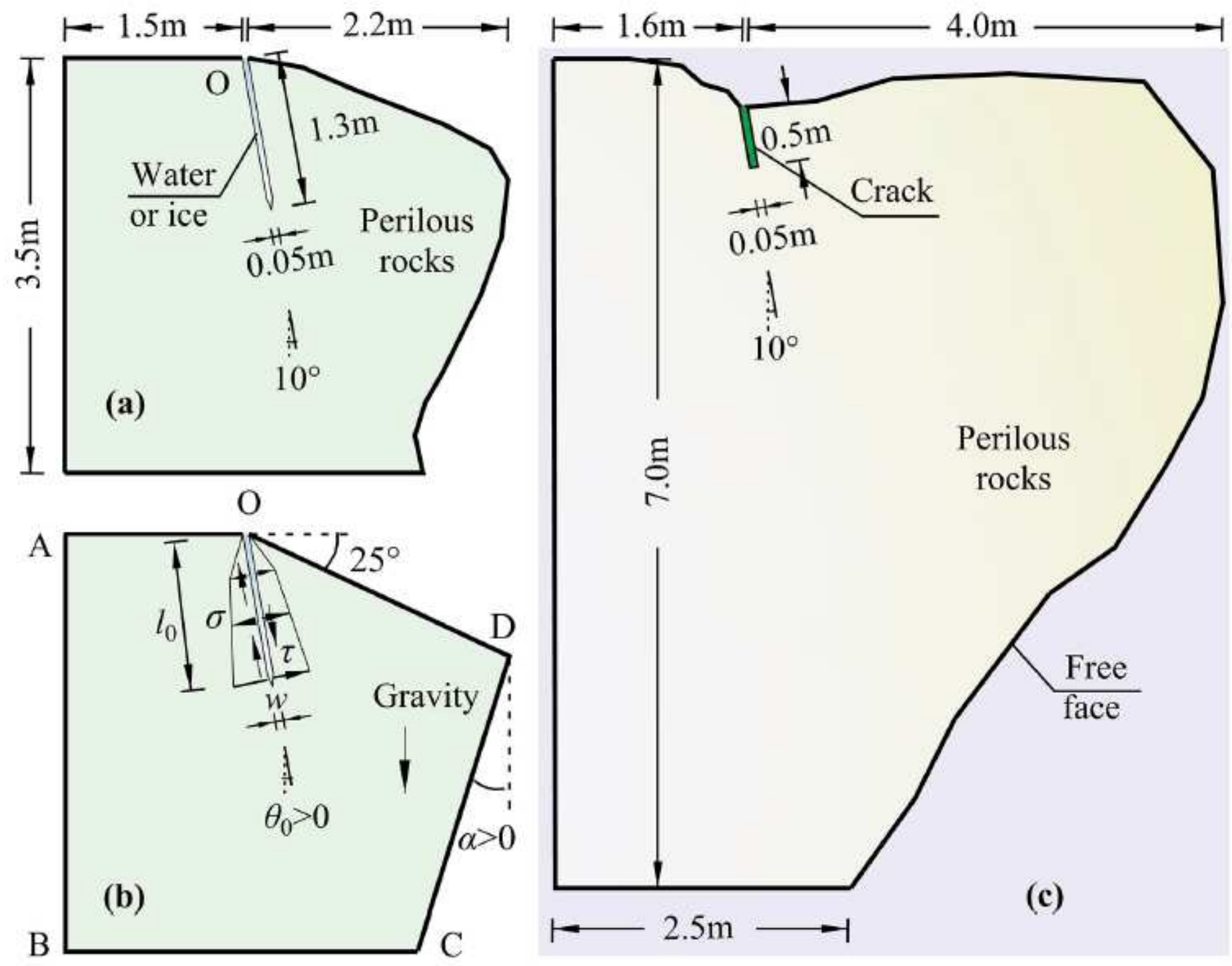

Figure 11

Computational analysis model of perilous rocks. 

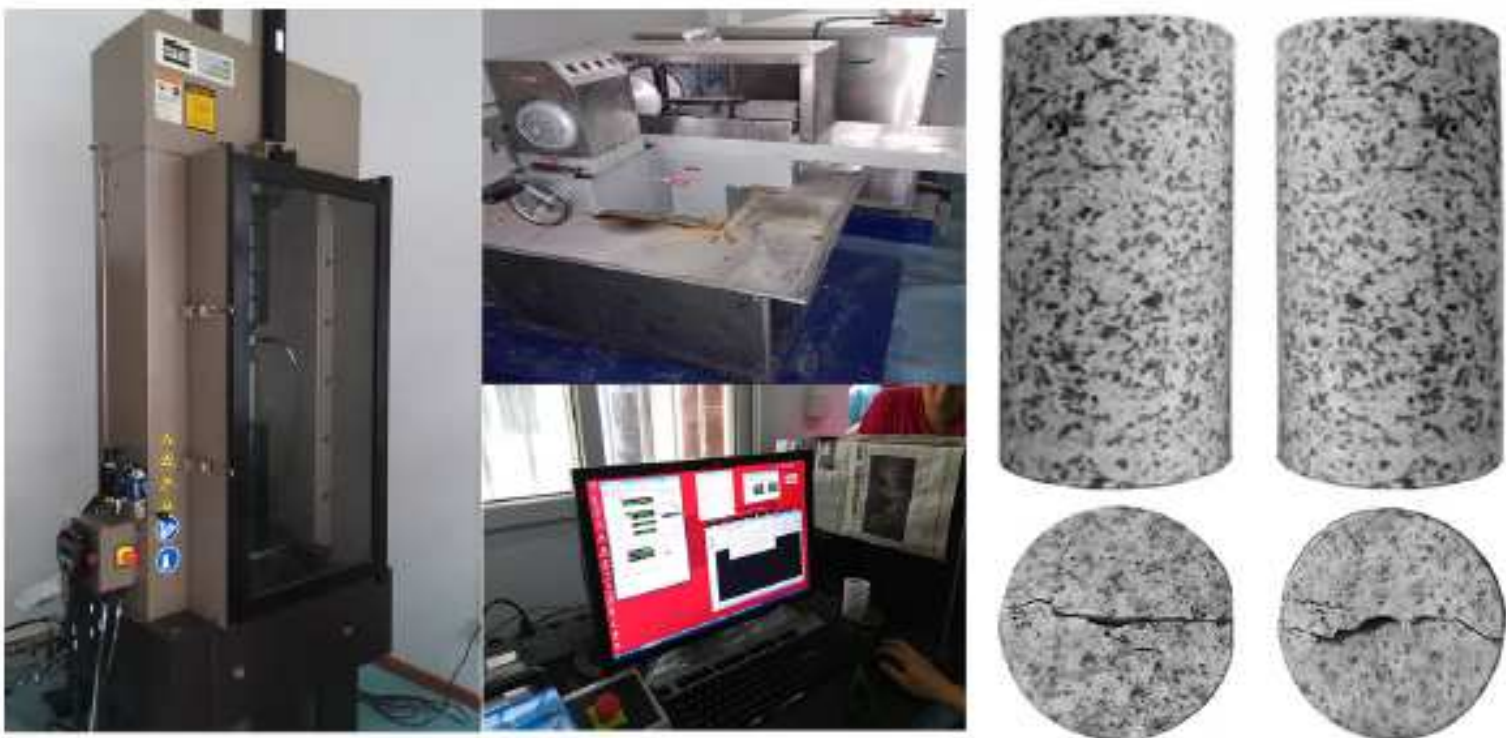

(a) Experimental instrument and specimens
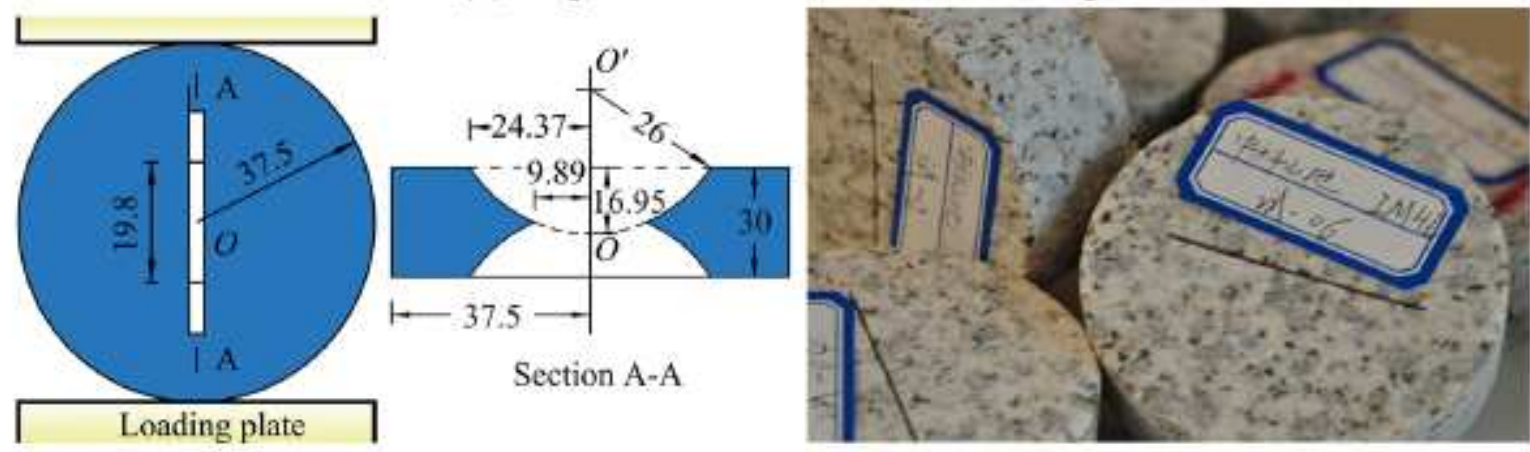

(b) The geometry of a CCNBD specimen
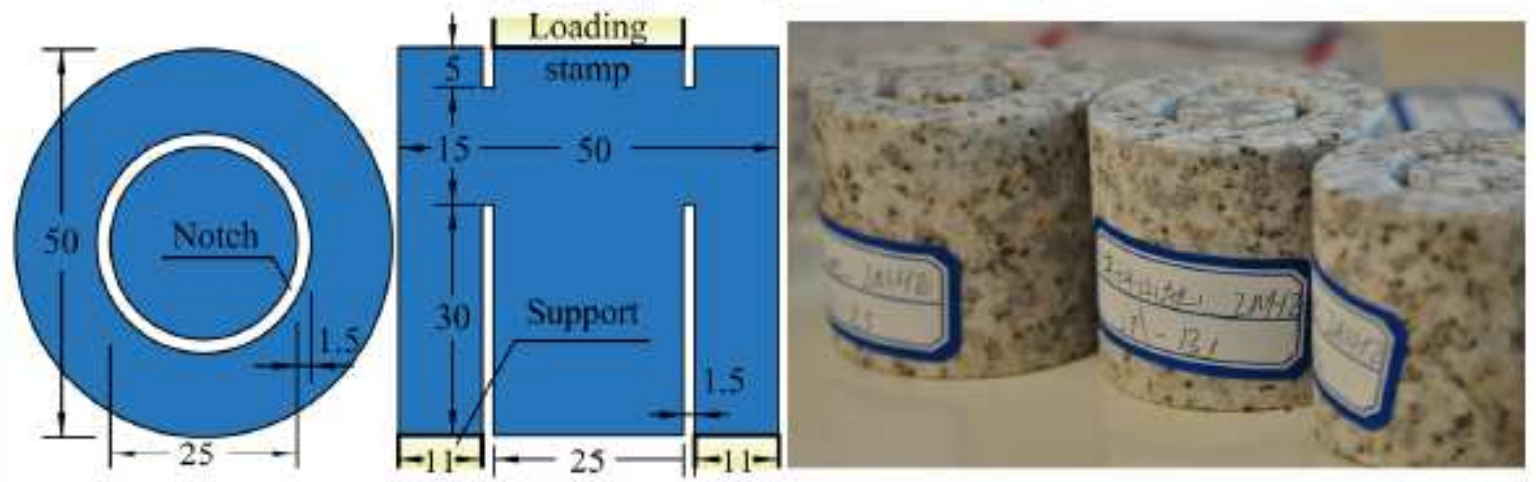

(c) The geometry of a PTS/CP specimen

Figure 12

Mechanical property test of granite 

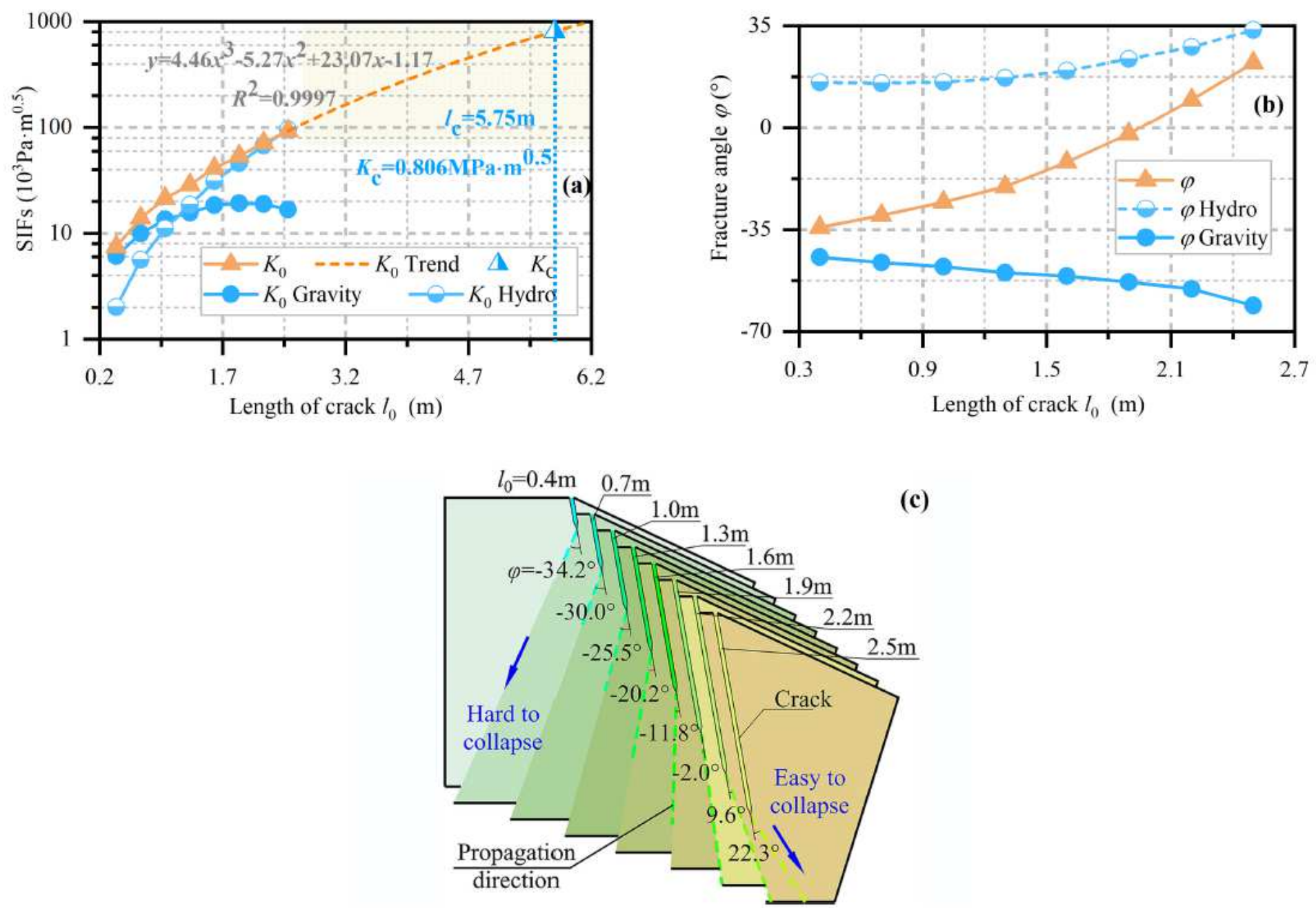

\section{Figure 13}

Influence of the crack length on (a) K0 and its contributions (b) fracture angle, and (c) propagation (case A). The suffixes (Gravity, Hydro) are used to mark the load conditions under rock gravity and hydrostatic pressure, respectively. 

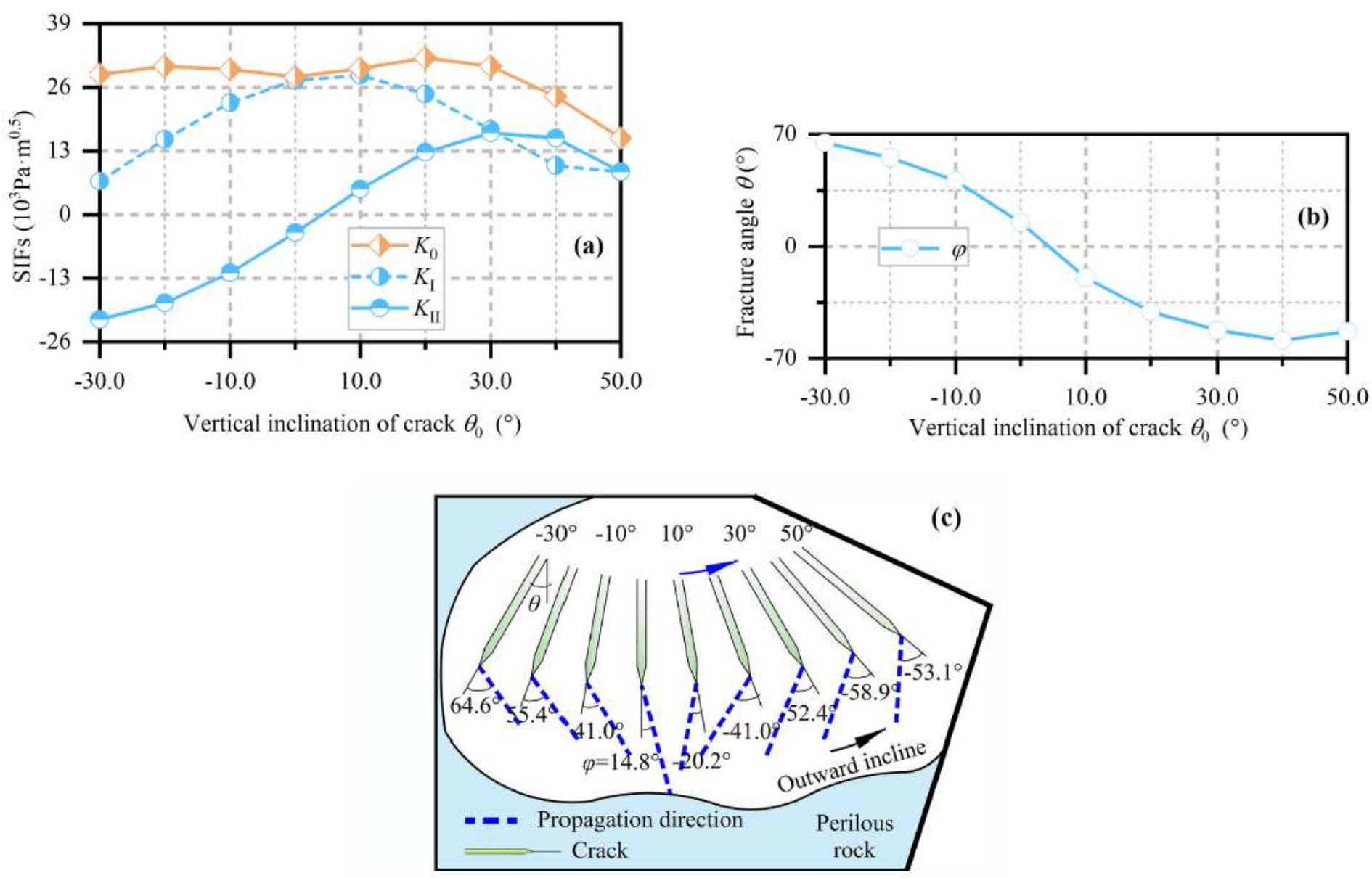

Figure 14

Change of (a) compound SIF KO, KI and KII, (b) fracture angle, and (c) crack propagation direction with the vertical inclination of crack (case B).

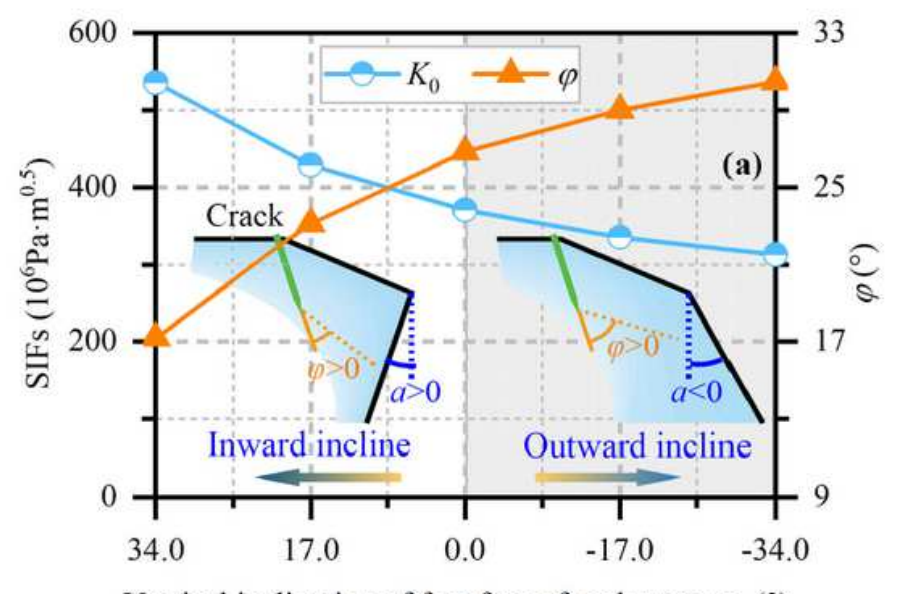

Vertical inclination of free face of rock mass $\alpha\left(^{\circ}\right)$

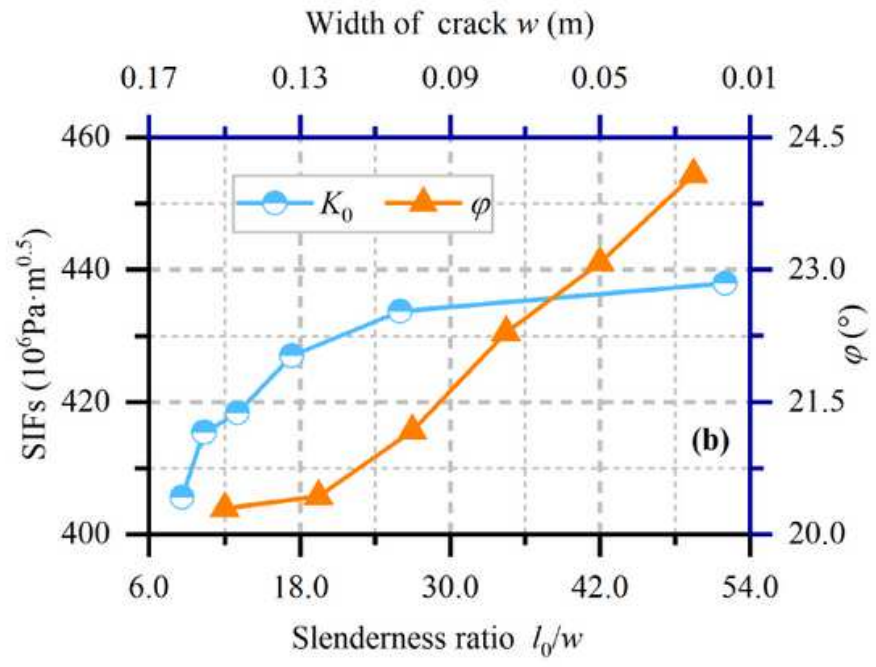

Figure 15

Variation of SIFs and $\varphi$ with (a) rock-free surface inclination a (case C) and (b) crack width w (case D) 

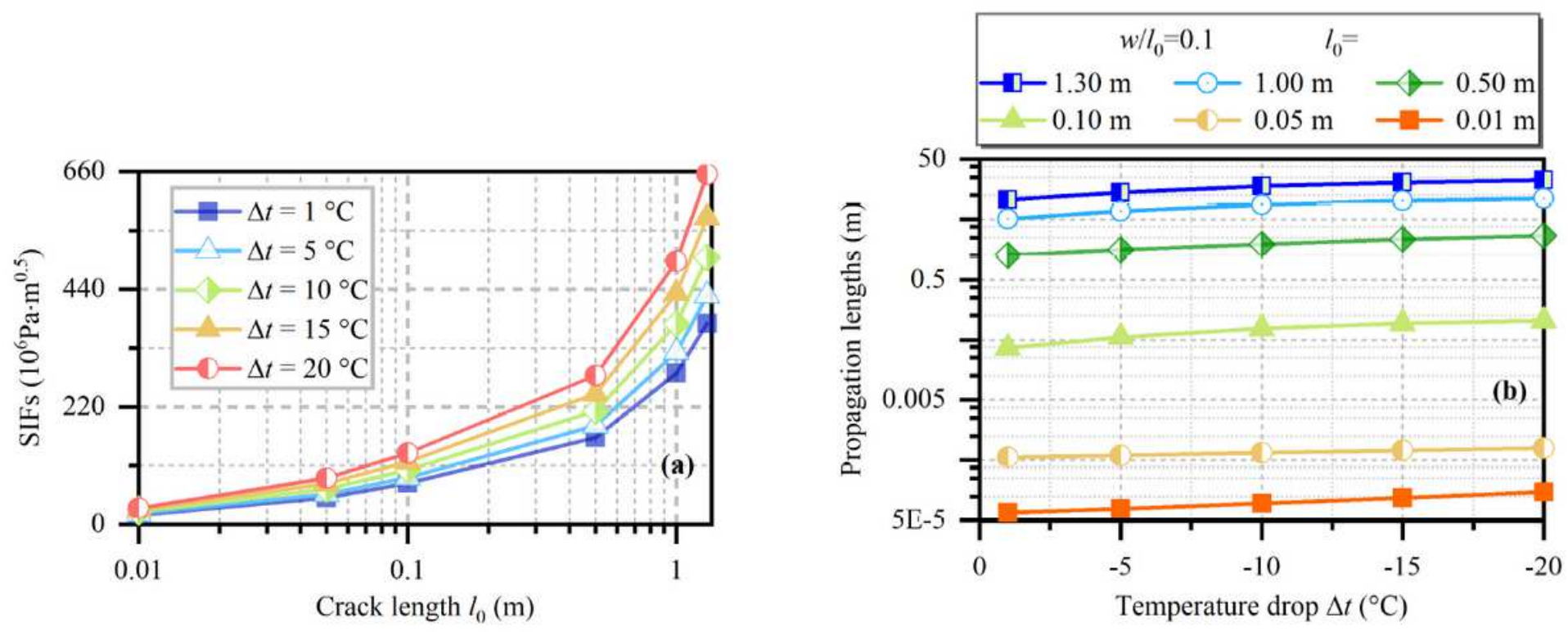

Figure 16

Effect of crack length and temperature drop $\Delta t$ on (a) SIFs and (b) propagation length (case E)
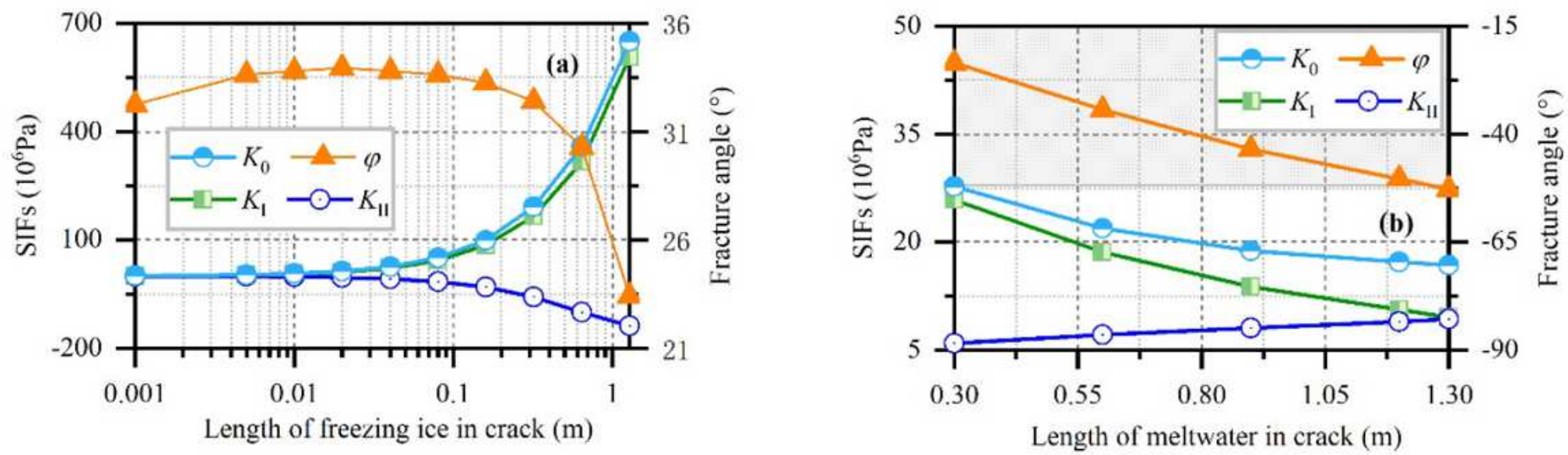

Figure 17

Variation of $\varphi, \mathrm{KO}, \mathrm{Kl}$, and $\mathrm{KIl}$ with the length of (a) freezing ice in autumn and (b) meltwater in spring. 

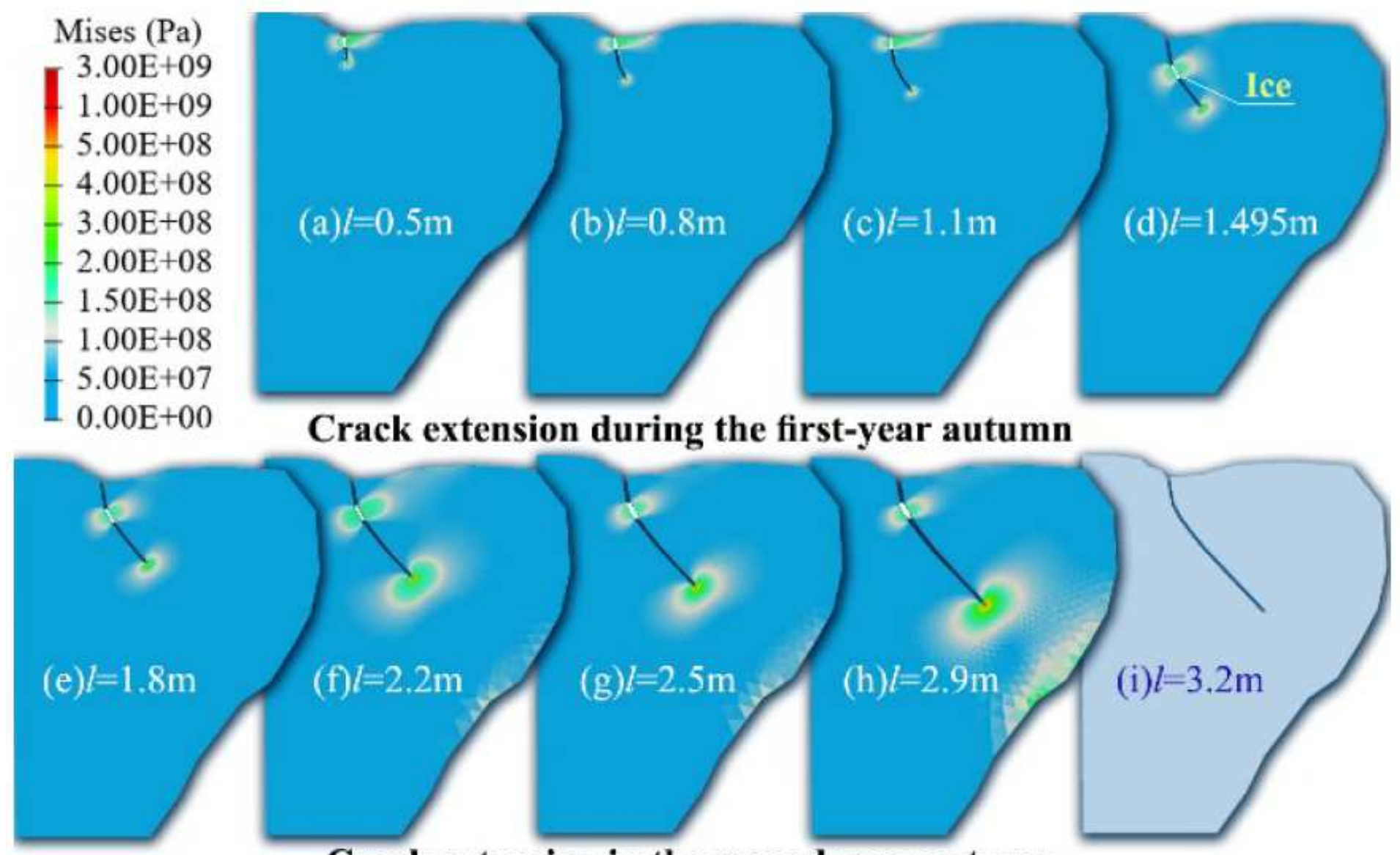

\section{Crack extension in the second-year autumn}

\section{Figure 18}

Evolution of crack path and stress contours of perilous rocks during the first $(a-d)$ and second $(e-i)$ autumn. (d) The final pattern of crack at the end of the first autumn and the initial stress state at the beginning of the second autumn. (i) The final pattern of crack at the end of the second autumn. 


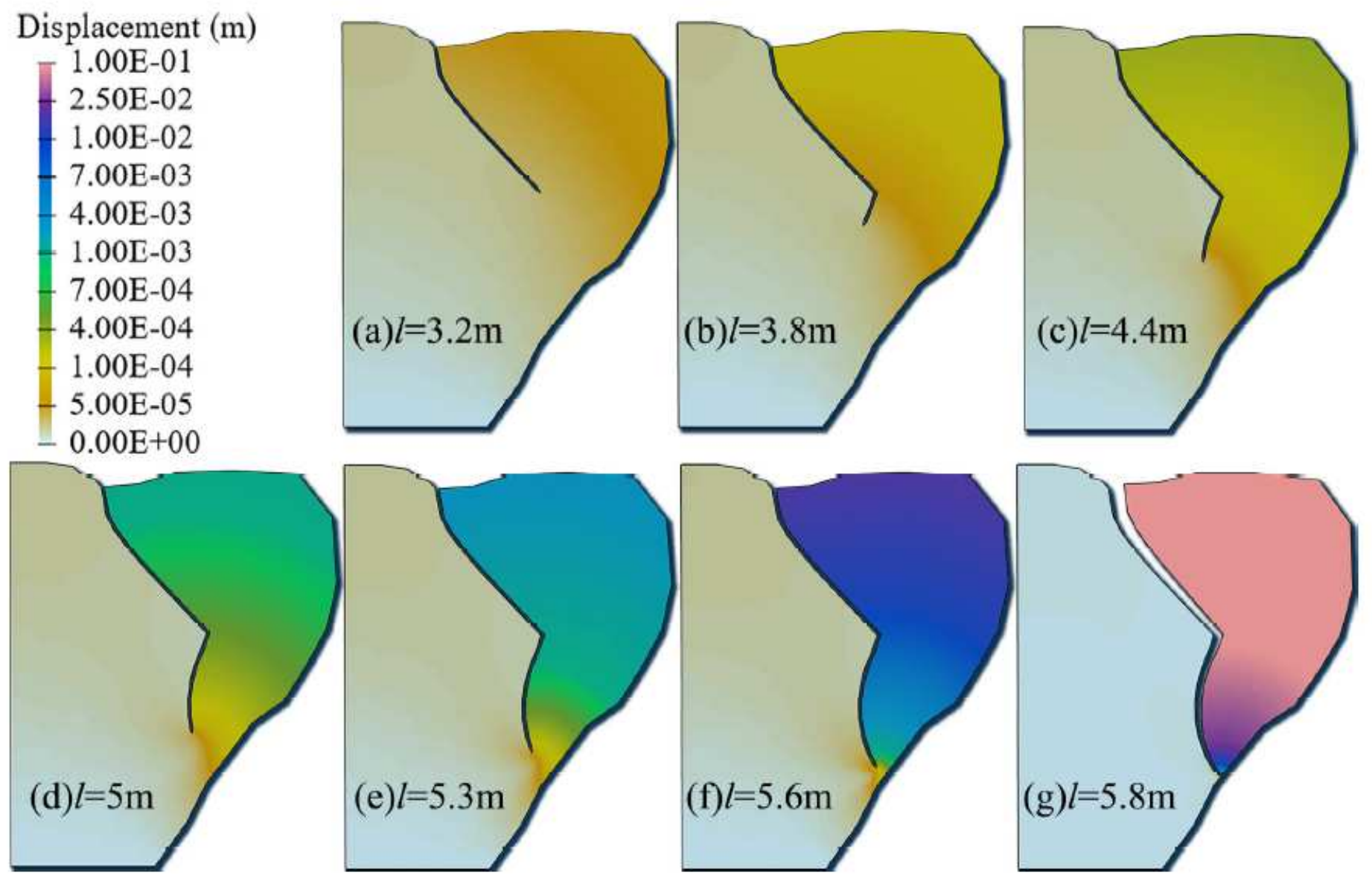

Figure 19

Crack propagation under hydrostatic pressure in the summer of the third year and the dynamic evolution of the collapse process. 